\title{
Experimental Investigation of Impact Response of RC Slabs with a Sandy Soil Cushion Layer
}

\author{
Jianli Wu, ${ }^{1}$ Guotao Ma, ${ }^{1}$ Zhenhua Zhou, ${ }^{2}$ Xuefeng Mei, ${ }^{3}$ and Xiewen Hu ${ }^{1,4}$ \\ ${ }^{1}$ Faculty of Geosciences and Environment Engineering, Southwest Jiaotong University, Chengdu 610031, China \\ ${ }^{2}$ State Key Laboratory of Geomechanics and Geotechnical Engineering, \\ Institute of Rock and Soil Mechanics Chinese Academy of Sciences, Wuhan 430071, China \\ ${ }^{3}$ School of Civil and Architectural Engineering, Shandong University of Technology, Zibo 255049, China \\ ${ }^{4}$ Engineering Laboratory Combined with National and Local of Spatial Information Technology of High Speed Railway \\ Operation Safety, Southwest Jiaotong University, Chengdu 610031, China
}

Correspondence should be addressed to Xiewen Hu; huxiewen@163.com

Received 16 December 2019; Revised 6 November 2020; Accepted 28 December 2020; Published 18 January 2021

Academic Editor: Payam Shafigh

Copyright (c) 2021 Jianli Wu et al. This is an open access article distributed under the Creative Commons Attribution License, which permits unrestricted use, distribution, and reproduction in any medium, provided the original work is properly cited.

\begin{abstract}
The impact response of reinforced-concrete (RC) slabs covered with a sandy soil cushion layer was investigated using an outdoor rockfall impact test platform. Impact tests were carried out by releasing rockfalls with different weights from different heights to impact a combined structure. Test data included the acceleration duration curve of the rockfall, strain of the concrete slab at multiple measuring points, and midpoint displacement duration curve of the slab. The test results showed an exponential relationship between the impact force acting on the cushion layer surface and cushion layer thickness. An empirical formula was used to calculate the maximum penetration, and the result was in good agreement with the test value. In addition, the attenuation rate of the impact force acting on the cushion layer increased exponentially with the increase in the cushion layer thickness, and the peak impact force could be attenuated by approximately $70 \%$ at a thickness of $0.6 \mathrm{~m}$. Finally, the failure process and failure modes of the RC slabs were investigated.
\end{abstract}

\section{Introduction}

Rockfalls are one of the most common geological hazards in mountainous areas $[1,2]$. Due to their unpredictability and high-energy dynamic characteristics, rockfalls pose a huge threat to roads and infrastructure. In recent years, researchers have made significant progress in developing prevention and mitigation measures against rockfalls. Rockfall protection measures can be broadly divided into two categories: active protection and passive protection. Passive protection measures include flexible nets [3,4], sheds $[5,6]$, and retaining walls [7]. In practical engineering applications, compared with rock sheds and retaining walls, flexible nets are more likely to be destroyed [8], so sheds and retaining wall structures are still the most widely used mitigation measures [9].

To reduce the impact of rockfalls on rigid sheds or retaining walls, it is typically necessary to add energy- consuming components or cushion layers on the side of the structure that is in contact with the rockfalls to avoid brittle failure [10]. For instance, conventional rock-shed structures and pile-slab retaining walls (Figure 1) are mainly constructed from frames with a slab on the top or side that is covered with cushioning materials [11]. Therefore, the two main parts of an impact-resistant system are the concrete supports (such as slabs and columns) and cushioning materials. He and $\mathrm{Wu}$ [12] and Boukria et al. [13] carried out experimental and numerical studies on structurally dissipating rock-shed (SDR) structures. However, the supporting components need to be replaced when they reach a certain deformation, which is unfavorable in engineering applications. Therefore, using a cushion layer to dissipate the energy of the rockfalls is currently the most common method. The cushion layer can dissipate the contact force between the rockfall and cover slab, reduce the acceleration of the rockfall, and extend the action time of the rockfall impacting 
the cover slab, thereby reducing the peak impact force and secondary hazards due to rockfall fragments [14]. From an economic perspective, gravel and soil are often used as cushion layer materials in engineering [15]. As a porous, loose, and easily compressible granular material, sand or gravel soil has the characteristics of both fluid and solid phases, and the wave propagation inside these materials exhibits extremely strong dispersion characteristics [16, 17], so they are widely used in protective structures. Many scholars have conducted research studies on the energy dissipation characteristics of sand or gravel soils. Ho et al. [18] conducted a test and theoretical analysis on a sandy soil cushion layer. Visco et al. [19] confirmed that the kinetic energy transmitted per unit area inside granular materials decreases as the depth increases. In addition to gravel soil, other materials have been employed in structural cushion layers. Gerber et al. [20] proposed foam glass and carried out large tests and a theoretical analysis; the results confirmed the excellent energy dissipating effect of the cushion layer. Zhao et al. [2] studied the cushioning effect of different combinations of steel shed-rock and sand, EPE, and expanded polystyrene (EPS) based on model tests. Gao et al. [21] studied the cushioning characteristics of foamed aluminum on reinforced-concrete (RC) slabs under explosive loading. Wang et al. [22] put forward a cushion layer composed of polyurethane foam and conducted experiments and numerical simulations.

The studies mentioned above mainly focused on the selection of the cushion layer, which has a low relative stiffness in the impact-resistant system. The conventional method is to use a certain thickness of granular materials (sand or soil). During the impact of rockfalls, the soil cushioning layer can be penetrated and therefore accumulates a large amount of irreversible deformation, which leads to a large plastic deformation and thus energy dissipation. If the soil layer thickness is sufficient, the large difference in the stiffness and strength between the cushion layer and RC slab can help ensure that the rigid support is in an elastic state, thereby increasing the durability of the protective structure. In addition, many studies have been carried out on an entire antirock impact system. Calvetti et al. [23] proposed a soilstructure interaction mechanism and its influence on the contact stress of the soil layer outside the diffusion zone of the impact force. Prisco and Vecchiotti [10] proposed a viscoelastic constitutive model to explain the process of shock waves penetrating the soil layer. Lorentz et al. [24] proposed a sandwich structure composed of an RC slab (Figure 2), gravel, and tires and studied its performance through tests. Kishi et al. [25] proposed a three-layer absorbing system. The system was composed of three materials: a $50-100 \mathrm{~cm}$ thick layer of EPS as the bottom layer, a $20-30 \mathrm{~cm}$ thick RC core slab, and a $50 \mathrm{~cm}$ thick sand cushion as the top layer. Hu et al. [11] simulated the dynamic response in a pile-slab retaining wall structure due to rockfall impact at different speeds and incident angles. Specifically, they analyzed the contact force, displacement, damage, and energy of the structure due to the impact load. The design of the cushion layer is extremely important for the safety of antirock impact structures, particularly the selection of the cushion layer thickness. Although a thicker cushion layer can resist greater impact energy, a thicker cushion layer increases the weight and causes a higher static load. Currently, the selection of the cushion layer thickness is based on experience, and there is no scientific and standardized system. According to the Guidelines for Design of Highway Tunnel in China [26], the soil cushion thickness should be greater than $1.5 \mathrm{~m}$ to resist rockfalls.

In this study, a rockfall impact test was designed, and two spherical rockfall models and two cubic rockfall models with different masses were fabricated. The paper reports test data such as the acceleration duration curve of the rockfall with varying mass and impact height, strain response of the RC slab at multiple measuring points, and duration curve of both the dynamic load on the RC slab surface and midpoint displacement of the slab after impact. First, based on the acceleration data, the relationship between the impact force on the cushion layer surface and cushion layer thickness was obtained, and the optimal cushion layer thickness was determined accordingly. Second, based on the experimental data, a dimensionless factor was proposed to quantitatively describe the transmission law of the impact force in the cushion layer. Finally, the failure process and dynamic failure modes of the RC slabs under different impact conditions were investigated. Overall, the experimental results in this study can serve as a basis for the design and optimization of protective structures aiming at rockfall disasters.

\section{Outline of the Experiment}

2.1. Experimental Design. An outdoor test platform for the rockfalls impacting RC slabs covered with an overlying cushion layer was built (Figure 2). The hoist at the top of the truss was used to lift and release the rockfall at different heights, and the designed maximum lifting height was $7 \mathrm{~m}$. A typical rockfall impact system should include two components: a rigid support and a cushion layer. The rigid components are generally made of concrete to support a certain thickness of the cushion layer, such as the roof of the shed structure or the retaining plate of the retaining wall. Although a prototype experiment can reveal the real physical process, it is typically destructive. Hence, it is uneconomical and requires a special technology [2]. In addition, there is no standard for the size of the actual rockfall-resistant structure, and it should be judged according to a designer's experience or site conditions. For example, the thickness of a shed roof or of the retaining plate of a retaining wall is considered to be in the range of $0.3-1.0 \mathrm{~m}$, whereas the thickness in the other two directions should be judged comprehensively (such as based on the required space and height of the rockfall). In this study, an actual engineering structure is simplified as a composite model in which an RC slab is covered with a sand soil cushion layer of different thicknesses based on our experimental conditions and the actual structure. The specific simplified model mainly includes an RC slab with a length of $2.4 \mathrm{~m}$, a width of $1.6 \mathrm{~m}$, and a thickness of $0.25 \mathrm{~m}$ and sandy soil cushion layers of different thicknesses covering the slab. The concrete is made from 42.5 grade Portland cement, and the coarse aggregate is made of gravel 


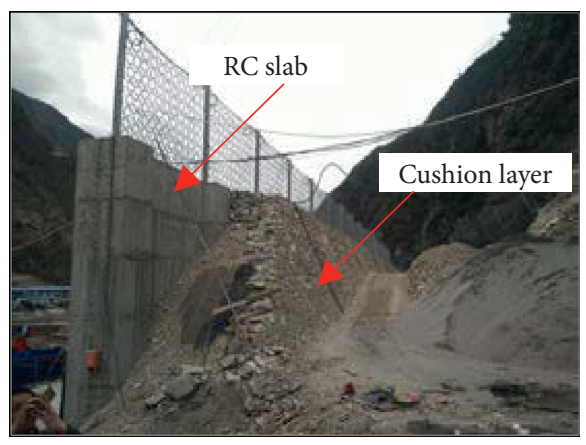

(a)

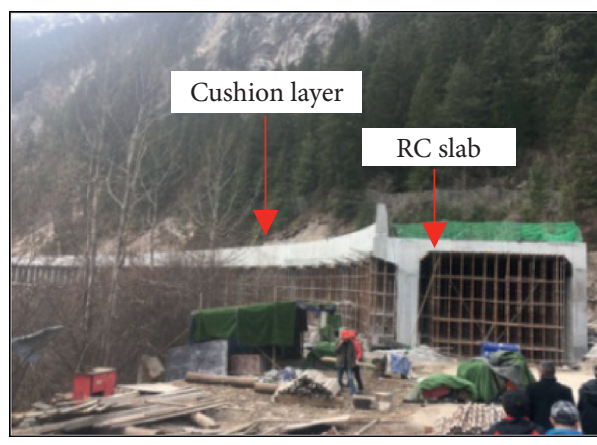

(b)

Figure 1: The RC slab with a cushion layer. (a) The pile-slab retaining wall in Kangding [11]. (b) Shed-rock in Jiuzhaigou.

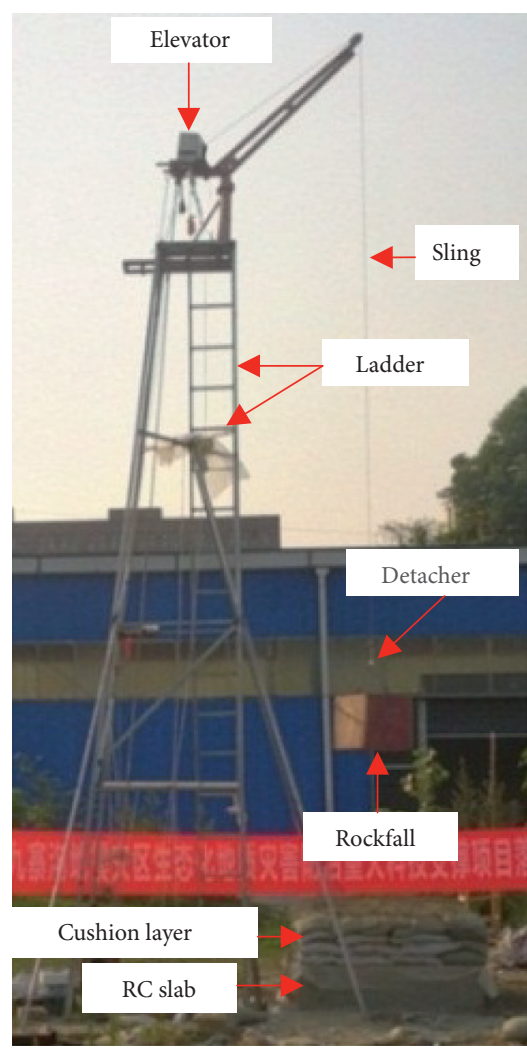

(a)

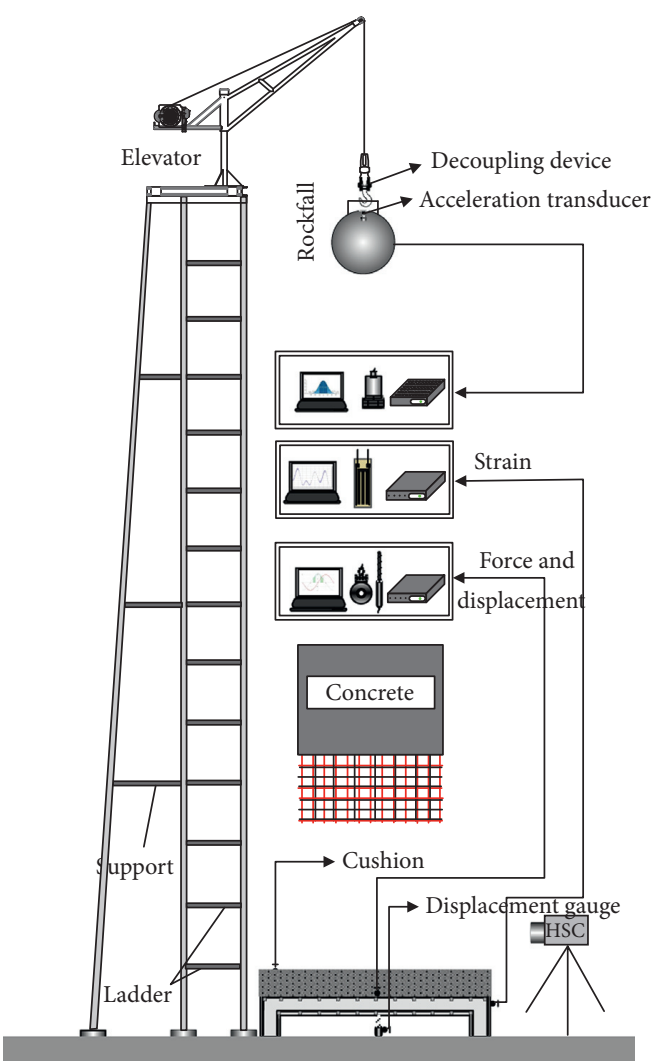

(b)

FIgURE 2: Impact test setup.

with a continuous particle size in the range of $5-15 \mathrm{~mm}$. The fine aggregate is made of natural fluvial sand, and the mixing ratio is cement: water: sand : stone $=1: 0.5: 1.5: 2.8$ [27]. Two layers of rebar meshes with a diameter of $14 \mathrm{~mm}$ and a spacing of $200 \mathrm{~mm}$ are laid perpendicular in the concrete slab. The concrete protective layer is $20 \mathrm{~mm}$ thick.

Typically, natural rockfalls have different shapes. In the existing literature, rockfall models of various shapes were used for impact testing and analysis, with the most typical ones being spherical [28-30], polyhedral [2], cubic [7, 31], and oval [32]. In our experiments, the material used to simulate the rockfalls was obtained by pouring concrete into steel molds. We used two cubic models of different sizes, denoted by $C 1$ and $C 2$, with side lengths of $0.35 \mathrm{~m}$ and $0.5 \mathrm{~m}$, respectively. They weighed $107.3 \mathrm{~kg}$ and $290.8 \mathrm{~kg}$, respectively. At a maximum impact height of $7 \mathrm{~m}$, the corresponding maximum impact energies were $7.4 \mathrm{~kJ}$ and $20.0 \mathrm{~kJ}$, respectively. In addition, we used two spherical models 
denoted by $B 1$ and $B 2$, respectively, with radii of $0.15 \mathrm{~m}$ and $0.2 \mathrm{~m}$, respectively, and they weighed $32.4 \mathrm{~kg}$ and $70.7 \mathrm{~kg}$, respectively, corresponding to maximum impact energies of $2.2 \mathrm{~kJ}$ and $4.9 \mathrm{~kJ}$, respectively.

2.2. Cushion Material Properties. According to engineering practices, sand and gravel soils are widely used in practical engineering owing to their wide distribution, low cost, and convenient accessibility. The cushion layer used in this study was made from local soil materials. To ensure the uniformity of the sample and to protect the strain gauge and force sensor installed on the surface of the RC slab, larger pieces of gravel were removed. After each impact experiment, the soil in the area larger than the impact range was removed and refilled again, and the filling was applied with the same pressure 10 times every $20 \mathrm{~cm}$. During the experiment, the cutting ring was used for sampling. Subsequently, we carried out density, water content, and particle grading tests on the soil material. Table 1 lists the parameters of the cushion layer. The average density of the soil particles was $1.54 \mathrm{~g} / \mathrm{cm}$. Figure 3 shows the particle gradation curve. According to the gradation curve, the average particle diameter of the soil materials is $D_{50}=0.1 \mathrm{~mm}$, nonuniform coefficient $C_{u}=35.2$, and curvature coefficient $C_{c}=0.31$.

2.3. Data Collection Strategy. The test data first involved the acceleration of the rockfall during the impact process, and thus, the product of the acceleration and rockfall weight was further used to obtain the impact force during the impact process $[33,34]$. Slots were made on the top of each rockfall, and a magnetic base was used to fix the accelerometer, which was a piezoelectric sensor with a range of $1000 \mathrm{~g}$ and a sampling frequency of $10 \mathrm{kHz}$. The upper and lower surfaces of the RC slab and rebar mesh in the RC slab were equipped with resistive strain gauges. The upper and lower layers of the strain gauges were installed in the same manner, as shown in Figure 4. Moreover, a displacement sensor with a range of $50 \mathrm{~mm}$ was installed at the center point of the lower surface of the RC slab. A dynamic pressure sensor with a maximum range of $5000 \mathrm{kPa}$ was arranged at the center point of the upper surface of the RC slab. The sampling frequency of the displacement sensor and pressure sensors was $50 \mathrm{kHz}$. To avoid the effects of soil backfilling under different impact conditions, the data acquisition instrument should be reset before each impact test so that the result obtained represents only the load effect due to a single impact of a rockfall.

\section{Experimental Results and Analysis}

\subsection{Mechanical Analysis of the Cushion Layer}

3.1.1. Acceleration Analysis. Table 2 lists the conditions for each rockfall impact experiment. For the convenience of analysis, the serial numbers in this paper are uniformly expressed as follows: the rockfall number, cushion layer thickness-impact height, is represented as $B 1-0.5 \mathrm{~m}-6 \mathrm{~m}$. The acceleration curve during the impact process is quantitatively measured using an acceleration sensor installed in the top slot of the rockfall model. As shown in Figure 5, the typical experimental results show that the duration curve of the acceleration is divided into a compression loading phase and an unloading rebound phase, and the impact times in the two phases are symmetrically distributed. If the rockfall number and cushion layer thickness are fixed, the acceleration increases with the impact height. The impact time is negatively correlated with the impact height and positively correlated with the cushion layer thickness. When the cushion layer thickness is $0.1 \mathrm{~m}$, the impact time decreases dramatically. At an impact height of $7 \mathrm{~m}$, the impact times of $B 2$ rockfall are $40 \mathrm{~ms}$ and $10 \mathrm{~ms}$, respectively, when the cushion layer thickness varies from $0.5 \mathrm{~m}$ to $0.1 \mathrm{~m}$, respectively. At the same impact height, the latter peak acceleration is 3-6 times that of the former, which means that increasing the cushion layer thickness can effectively reduce the impact force of the rockfall. Considering that the rockfall is infinitely rigid compared with the soil materials, according to Newton's law, the peak incident impact force acting on the surface of the cushion layer is defined as

$$
F_{0}=m a
$$

where $F_{0}$ is the incident impact force $(\mathrm{N})$ on the surface of the cushion layer, $m$ is the rockfall weight $(\mathrm{kg})$, and $a$ is the rockfall acceleration $\left(\mathrm{m} / \mathrm{s}^{2}\right)$.

Existing calculation formulae for the impact force generally assume that the cushion layer thickness has no effect on the peak impact force $[33,35]$. However, the measured data in this study show (Figure 6) that, as the cushion layer thickness decreases, the peak acceleration and cushion layer thickness follow an exponential relationship. When the cushion layer thickness ranges from $0.3 \mathrm{~m}$ to $0.6 \mathrm{~m}$, the peak acceleration varies gradually with the cushion layer thickness. However, when the cushion layer thickness is reduced to $0.1-0.2 \mathrm{~m}$, the slope of the curve changes sharply, and the impact time is evidently narrowed. At the same impact height, the peak acceleration corresponding to a $0.1 \mathrm{~m}$ thick cushion layer is $2-4$ times higher than that corresponding to a $0.2 \mathrm{~m}$ thick cushion layer, which means that the cushion layer thickness is extremely sensitive to the amplification effect of the impact force of the rockfall. Therefore, the calculation formulae that do not consider parameters, such as the cushion layer thickness, significantly underestimate the maximum impact force of rockfalls, which may be one of the main reasons for the damage of existing protective structures such as rock sheds.

\subsubsection{Analysis of the Relationship between Crater Depth and} Impact Force. As depicted in Figure 7, the impact zone can be divided into a direct impact zone and an impact disturbance zone, wherein a cavity is formed outside the rockfall and a ring-shaped bulge appears on the periphery of the cavity. Under the impact load, the unharmonious deformation of the direct impact zone and disturbance zone as well as the fluidity of the soil particles are the primary causes for the formation of cavities and bulges. In engineering, the 
TABLE 1: .Physical parameters of the cushion layer.

Natural density $\left(\mathrm{g} / \mathrm{cm}^{3}\right)$ Elasticity modulus $(\mathrm{MPa})$ Water content (\%) Poisson's ratio Internal friction angle $\left({ }^{\circ}\right)$ Resilience coefficient

\begin{tabular}{llllll}
\hline 1.54 & 15 & 5.39 & 0.27 & 30 & 0
\end{tabular}

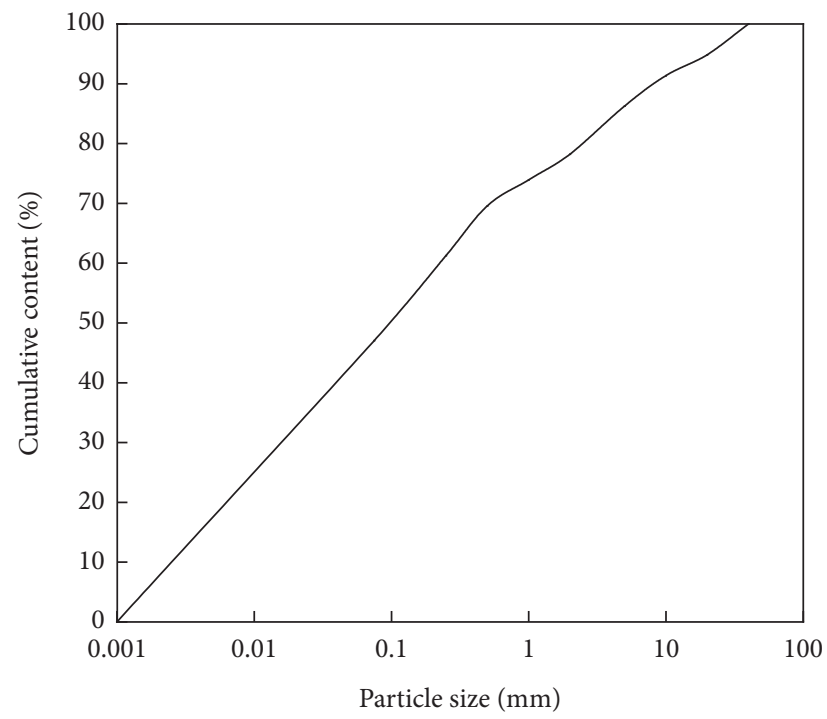

FIgURE 3: Particle size distribution of the cushion layer.

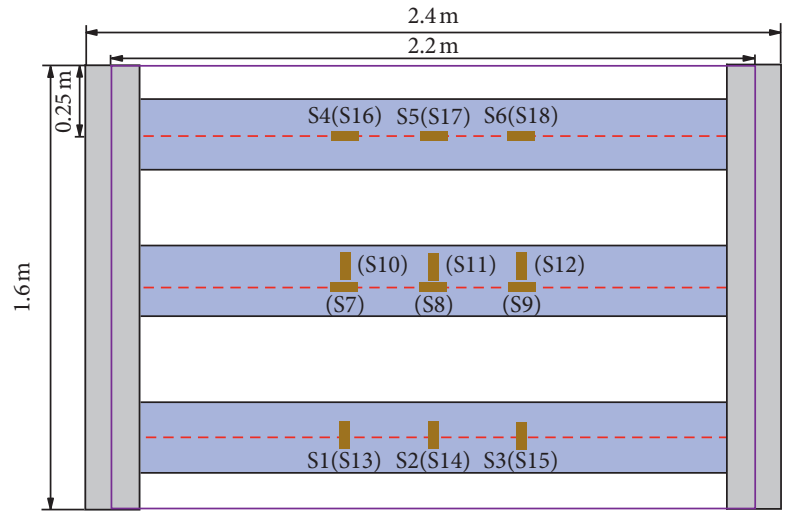

(a)

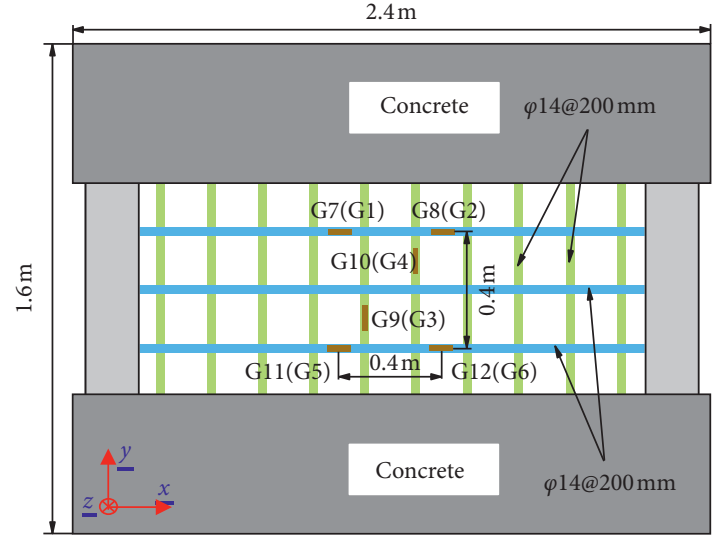

(b)

FIgURE 4: The layout of strain gauges (the numbers in the parentheses refer to the strain gauges at the bottom of the RC slab). (a) Concrete. (b) Rebar.

TABLE 2: The conditions for each impact experiment.

\begin{tabular}{lccccc}
\hline $\begin{array}{l}\text { Rockfall } \\
\text { number }\end{array}$ & Cushion layer thickness (m) & Impact height $(\mathrm{m})$ & Rockfall weight $(\mathrm{kg})$ & Rockfall volume $\left(\mathrm{m}^{3}\right)$ & Maximum impact energy $(\mathrm{kJ})$ \\
\hline$B 1$ & $0.1 \sim 0.6$ & $4 \sim 7$ & 32.4 & 0.014 & 2.2 \\
$C 1$ & $0.1 \sim 0.6$ & $1 \sim 7$ & 107.3 & 0.043 & 7.4 \\
$B 2$ & $0.1 \sim 0.6$ & $4 \sim 7$ & 70.7 & 0.033 & 4.9 \\
$C 2$ & $0.5 \sim 0.6$ & $1 \sim 7$ & 290.8 & 0.125 & 20.0 \\
$C 2$ & 0.4 & $1 \sim 6$ & 290.8 & 0.125 & 17.1 \\
\hline
\end{tabular}



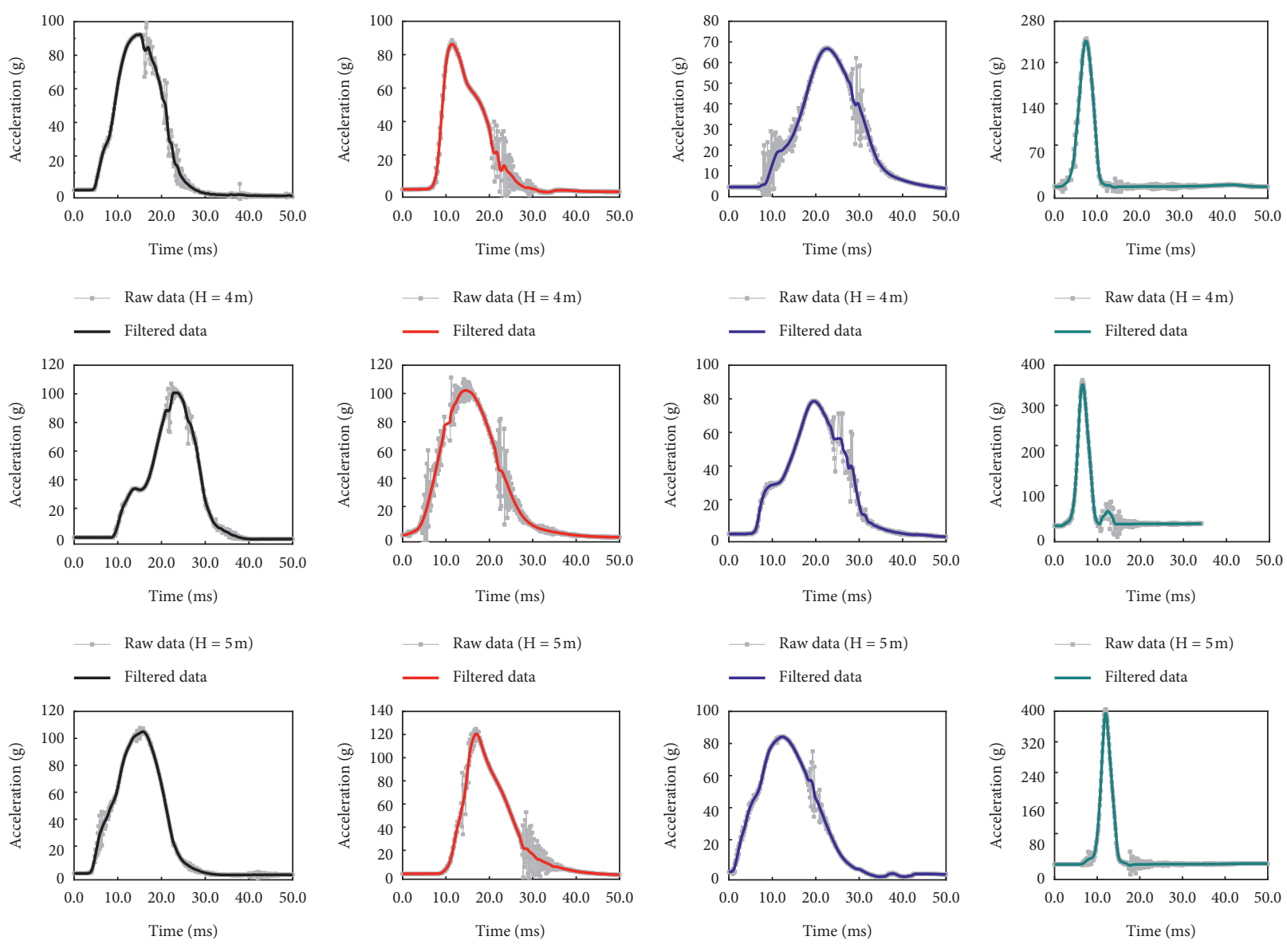

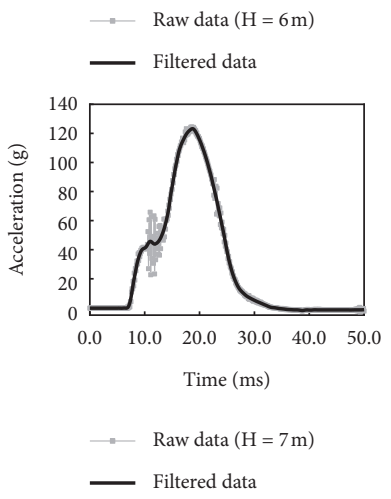

(a)

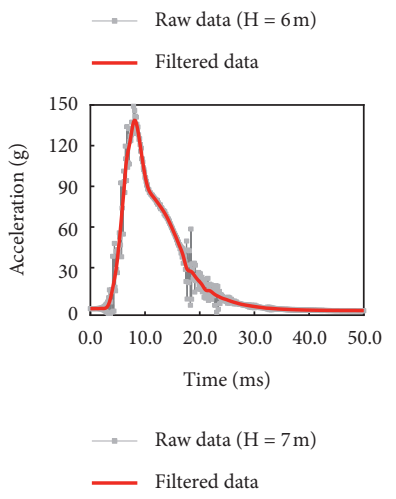

(b)
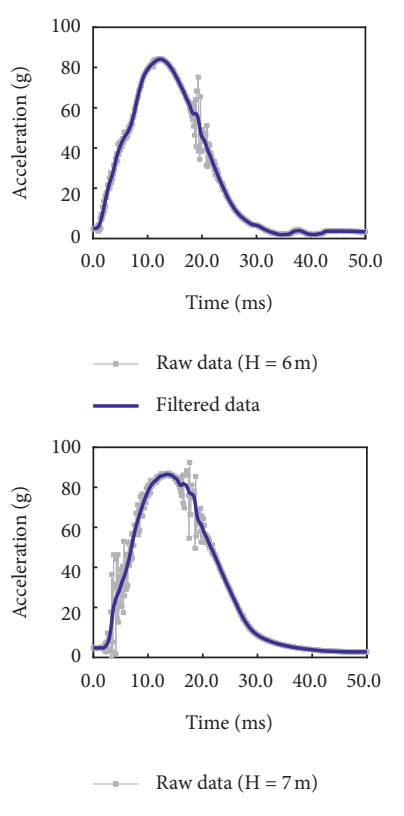

(c)

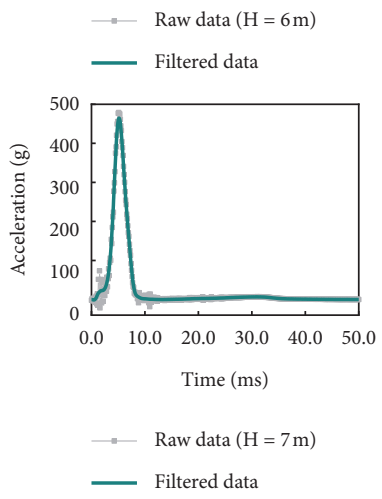

(d)

FIGURE 5: Duration curves of the acceleration obtained from rockfall impact experiments (200 Hz FFT). (a) B1-0.4 m. (b) C1-0.5 m. (c) $B 2-0.5 \mathrm{~m}$. (d) $B 2-0.1 \mathrm{~m}$.

maximum crater depth often serves as the design basis for the minimum cushion layer thickness. According to the elastoplastic theory and LS-DYNA, Wang et al. [36] established a calculation method for the penetration of rockfalls impacting the soil layer. Ronco et al. [7] used a numerical simulation to analyze the variation in the depth. Wang and Cavers [31] derived a method for calculating the rockfall penetration using the energy principle. The Specification for Design of Highway Subgrades (SDHS) [37] provides an empirical formula for calculating the maximum crater depth. Based on the experimental results in this study, the calculation method for the maximum penetration of the crater can be obtained:

$$
\delta=\frac{m v^{2}}{F_{0}}=\frac{2 m g H}{F_{0}},
$$

where $m$ is the rockfall weight $(\mathrm{kg}), v$ is the maximum impact velocity, $\delta$ is the crater depth $(\mathrm{m}), H$ is the impact height $(\mathrm{m})$, $g$ is the gravitational acceleration $\left(\mathrm{m} / \mathrm{s}^{2}\right), g=9.81 \mathrm{~m} / \mathrm{s}^{2}$, and 


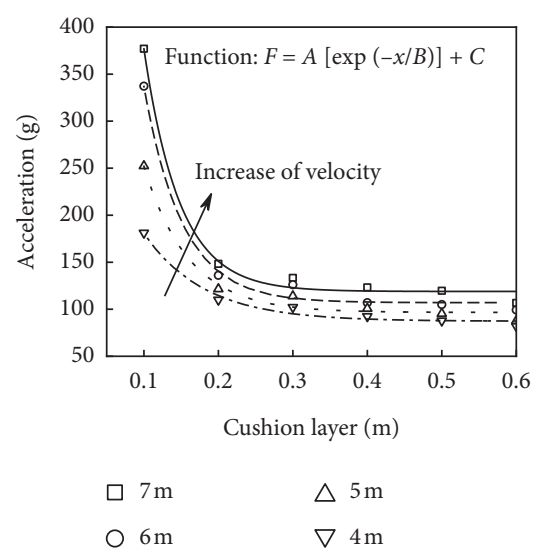

(a)

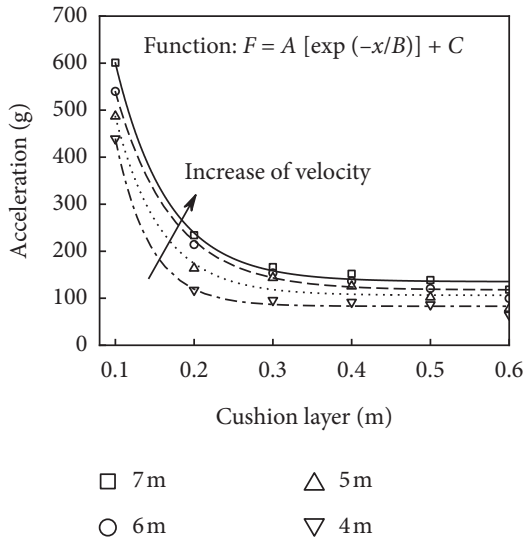

(b)

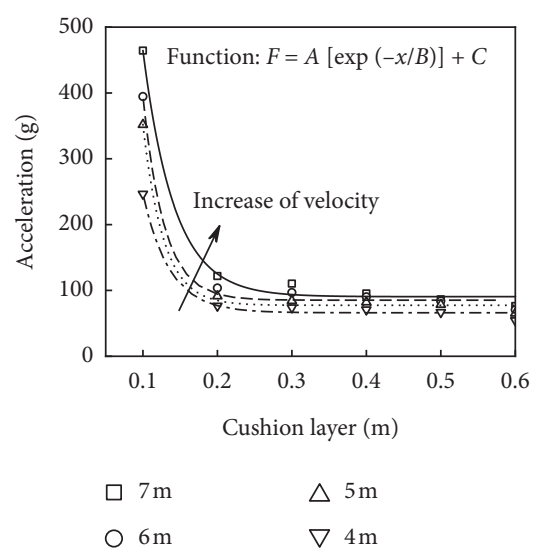

(c)

FIgURE 6: The relationship between the peak acceleration and cushion layer thickness. (a) B1 rockfall. (b) C1 rockfall. (c) B2 rockfall.

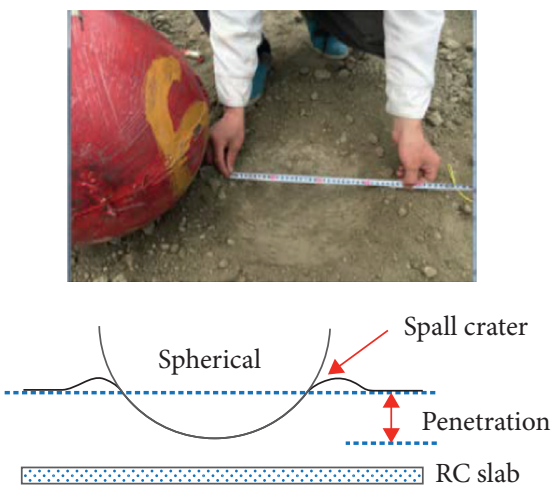

(a)

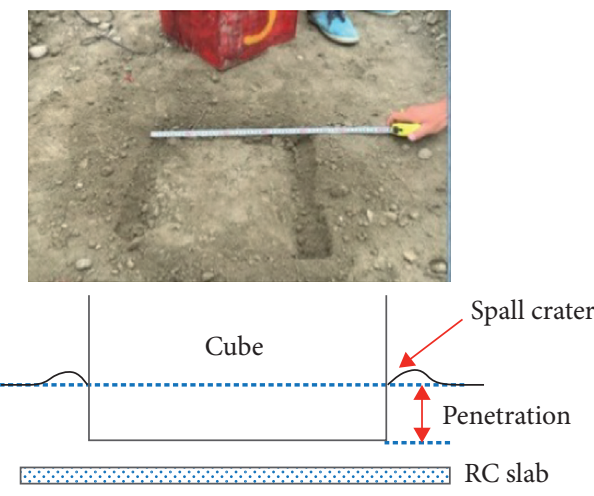

(b)

FIgURE 7: Typical patterns of craters during the impact process. (a) The arc-shaped crater. (b) The flat-bottomed crater.

$F_{0}$ is the maximum impact force $(\mathrm{N})$.

Therefore, equation (2) shows that the rockfall penetration is related to the impact velocity (or height) of the rockfall and maximum impact force. In practical engineering applications, these are the two most basic characteristic parameters. The maximum rockfall penetration can be calculated using equation (2) to further design the cushion layer thickness. To verify the validity of the formula proposed in this paper, the calculation methods proposed by other scholars are compared with the measured data from the rockfall impact experiments and proposed formula. Figure 7 shows the results, where the $x$-axis represents the measured data and the $y$-axis represents the values calculated by Wang [36], SDHS [37], and the proposed formula. As shown in Figure 8, the basic trends in these calculation results are consistent. Overall, the values obtained using the SDHS are higher than the measured values and those calculated using the other methods. The calculation model proposed by Wang et al. and the proposed method are consistent with the measured data. The partially discrete data points are mainly due to the tumbling of the cubic rockfall models during the impact process. Therefore, parameters, such as the internal friction angle of the cushion layer and the rockfall weight, should be considered in the SDHS [37], and the coefficient of restitution should be considered in the calculation formula proposed by Wang et al. [36]. Relatively, the calculation method proposed in this paper only involves two basic characteristic parameters, namely, the maximum impact force and impact velocity, which can avoid the difficulty in selecting complex parameters. Hence, its design basis for the minimum cushion layer thickness is scientific.

3.1.3. Analysis of Impact Force Attenuation. Considering that the impact energy is dissipated by the upper cushion layer, it is assumed that the incident impact force $F_{0}$ penetrates the cushion layer to the lower RC slab, point at which the resultant impact force $F_{1}$ is significantly reduced (Figure 9). The value of $F_{1}$ is obtained by integrating the transmitted force in the affected zone:

$$
F_{1}=\iint_{\sum} P_{i} d s_{i}
$$

where $P_{i}$ is the stress $(\mathrm{Pa})$ at the measuring point in the affected zone and $d s_{i}$ is the microcell area $\left(\mathrm{m}^{2}\right)$.

During the impact process of the rockfall, the incident shock wave diffuses deep into the cushion layer at a certain angle, which is called the diffusion angle. The railways tunnel 


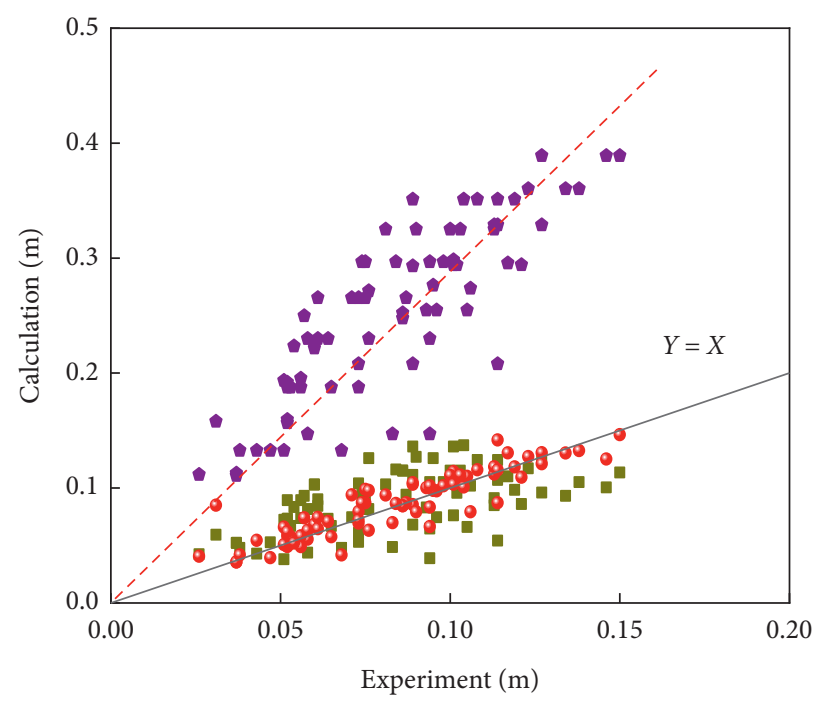

- SDHS
- WANG
- Model proposed

Figure 8: Comparison of tests and calculations from different methods.

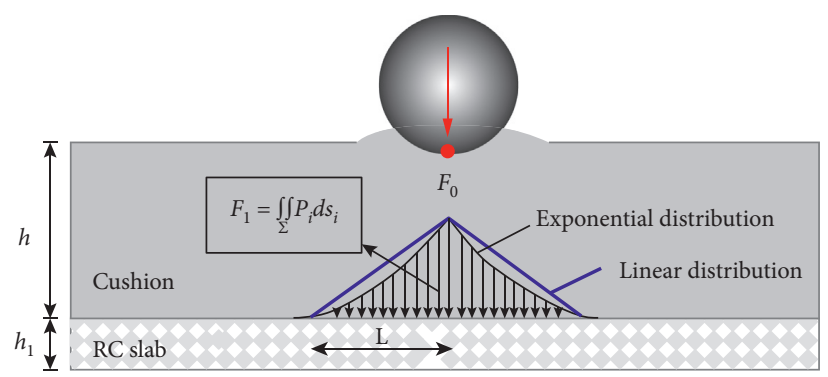

Figure 9: Diffusion and distribution characteristics of impact force.

design code [38] offers the specific value of the diffusion angle. Generally, the diffusion angle is related to the properties of the cushion layer. Based on the natural property of the soil materials used in this study [39], the diffusion angle and diffusion radius can be determined as follows:

$$
\left\{\begin{array}{l}
\theta=45^{\circ}-\frac{\varphi}{2}, \\
L=r+h \tan \theta,
\end{array}\right.
$$

where $\theta$ is the diffusion angle of the cushion layer $\left({ }^{\circ}\right)$, which is related to the property of the cushion layer, $\varphi$ is the friction angle of the soil material $\left({ }^{\circ}\right), h$ is the thickness of the cushion layer $(\mathrm{m}), L$ is the radius of the affected zone $(\mathrm{m})$, and $r$ is the equivalent radius of the rockfall model $(\mathrm{m})$.

The distribution forms of the transmitted force mainly include the exponential distribution $[10,40]$ and linear distribution $[41,42]$. In this study, we adopt the latter because it simplifies the calculation process significantly. Figure 10 presents the duration curve of the impact force recorded by the force sensor $P$ at the center point on the lower surface of the RC slab under different impact conditions. Since the force sensor is directly buried at the bottom of the cushion layer, the joint between the wire and sensor is frequently crushed when the cushion layer thickness is less than $0.3 \mathrm{~m}$, so the responding data cannot be obtained. Therefore, this section only discusses the case in which the cushion layer thickness is greater than $0.3 \mathrm{~m}$. The test results indicate that the duration curves of the transmitted force at different impact heights present the same variation law. Unlike the duration curve of the acceleration, the transmitted force skyrockets from 0 to the maximum value, showing no retardation phenomenon, and the entire impact duration is approximately $20 \mathrm{~ms}$. With the increase in the cushion layer thickness, there is an evident descent platform at the end of the curve, and then, it gradually reaches zero.

Moreover, the peak transmitted force is positively correlated with the impact height and weight of the rockfall. In this section, a parameter called the dimensionless peak impact force is defined to scale the attenuation effect of the incident impact force, as shown in the following equation: 


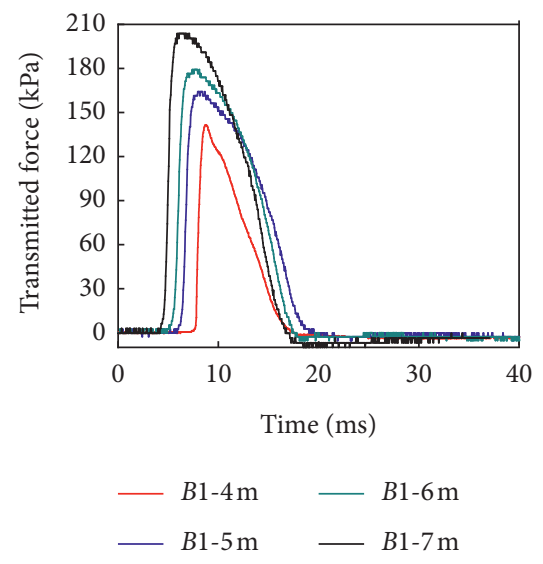

(a)

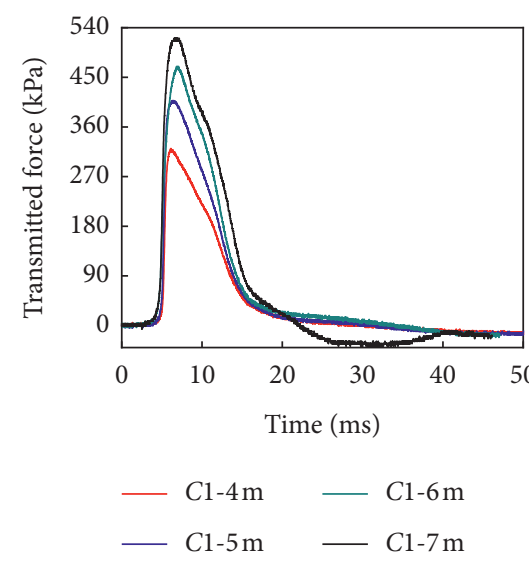

(d)

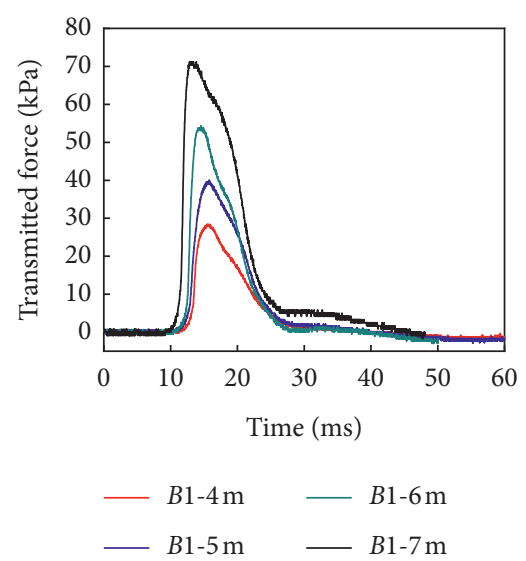

(b)

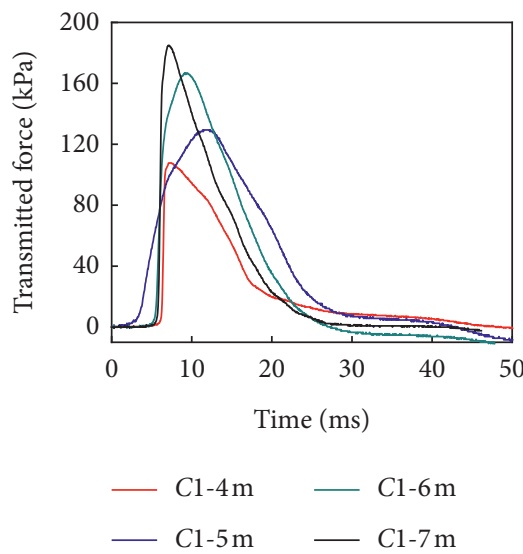

(e)

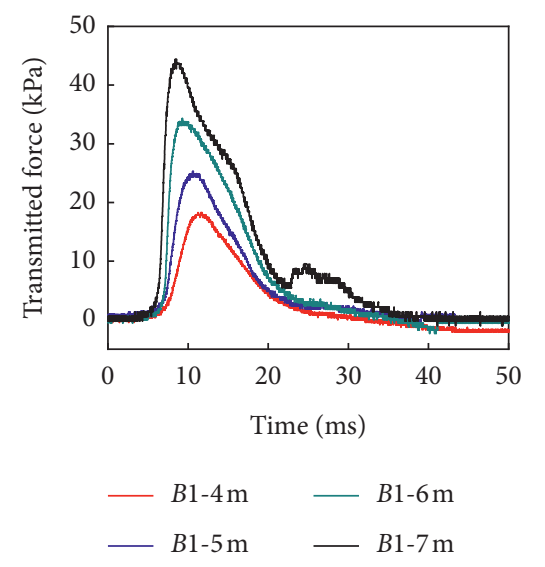

(c)

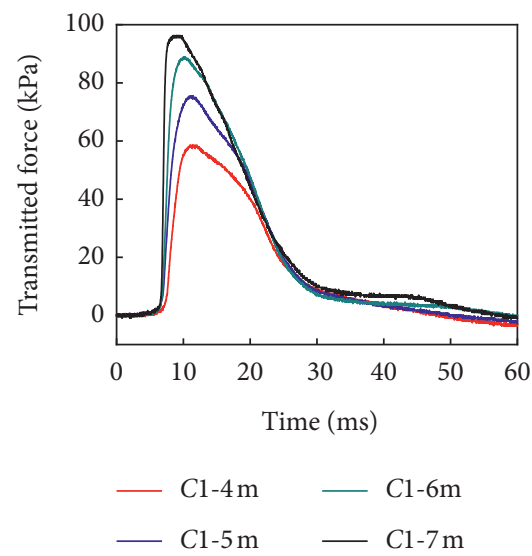

(f)

Figure 10: Duration curves of the transmitted force at different impact heights. (a) B1-0.3 m. (b) B1-0.5 m. (c) B1-0.6 m. (d) C1-0.3 m. (e) $C 1-0.5 \mathrm{~m}$. (f) $C 1-0.6 \mathrm{~m}$.

$$
\eta=\frac{F_{1}}{F_{0}}
$$

where $F_{0}$ is the incident impact force $(\mathrm{N})$ on the surface of the cushion layer and $F_{1}$ is the resultant force $(\mathrm{N})$ of the transmitted force acting on the surface of the RC slab.

Figure 11 shows the variation in the dimensionless peak impact force with the cushion layer thickness when the impact height is between $4 \mathrm{~m}$ and $7 \mathrm{~m}$. The attenuation laws of three different types of rockfall models under different cushion layer thicknesses are the same. There exists an exponential relationship between the dimensionless peak impact force and cushion layer thickness. As the cushion layer thickness decreases, the dimensionless peak impact force increases, and the degree of attenuation of the incident impact force keeps decreasing. The incident impact force of $C 1$ in the $0.3 \mathrm{~m}$ thick cushion layer is attenuated by $32 \%$. When the cushion layer is increased to $0.6 \mathrm{~m}$, the incident impact force is attenuated by $73 \%$, which proves that the energy dissipation effect of the cushion layer is significant. Compared with $B 1$ and $\mathrm{B} 2$, the attenuation effect of $C 1$ is slightly stronger under the same impact conditions, which may be due to the fact that the impact force acting on the flat-bottomed contact surface is easier to dissipate. Overall, the energy dissipation effect mainly depends on the material properties of the cushion layer, such as particle composition and gradation. In addition, as the cushion layer thickness increases, the attenuation value tends to be moderate, i.e., the attenuation effect of the cushion layer thickness becomes increasingly weaker. Here, the $C 1$ rockfall is taken as an example. When the cushion layer thickness is increased to $1.5 \mathrm{~m}$, the attenuation rate calculated by the attenuation theory proposed in this paper is greater than 90\%; however, a cushion layer with an excessive thickness is uneconomical (typically, there are site and economic constraints). Therefore, the attenuation curve proposed in this paper can help evaluate the influence of the cushion layer thickness on the attenuation of the incident impact force. The Levenberg-Marquardt algorithm is used for the fitting and an exponential function is obtained. The correlation coefficients of the fitting functions are greater than 0.95 , which proves that the fitting effect is better. The specific expression is

$$
\eta=\frac{F_{1}}{F_{0}}=A e^{-h / \lambda},
$$

where $A$ is the material parameter of the cushion layer and is related to the compactness and grain size distribution of the soil. For the cushion layer proposed in this paper, the fitting 


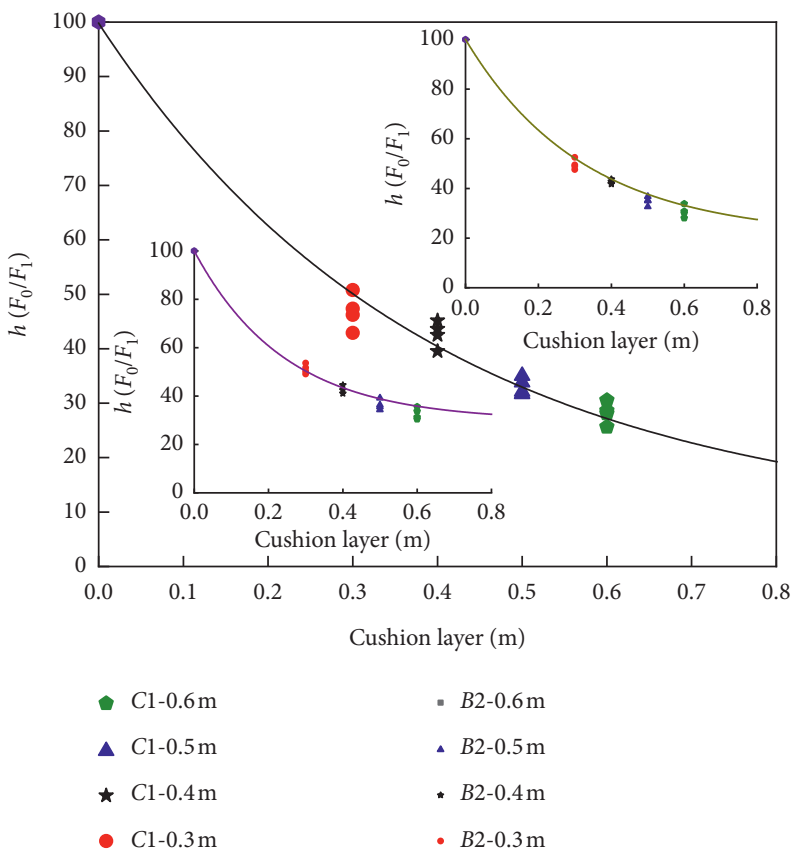

FIGURE 11: The relationship between dimensionless impact force and cushion layer thickness.

value $A=0.990 ; \lambda$ is the parameter related to the rock size. For $B 1$ rockfall, $\lambda=0.498 \mathrm{~m}^{-1}$, for $B 2$ rockfall, $\lambda=0.475 \mathrm{~m}^{-1}$, and for $C 1$ rockfall, $\lambda=0.456 \mathrm{~m}^{-1}$. Therefore, the larger the rockfall size, the lower the corresponding $\lambda$ value; $h$ is the cushion layer thickness $(\mathrm{m})$.

\subsection{Dynamic Response of RC Slabs}

3.2.1. Strain Analysis of Concrete and Rebar. Based on the measured results, the typical strain variations in the concrete and rebar with time are shown in Figures 12 and 13, respectively, where the positive values refer to the tensile strain and the negative values denote the compressive strain. Figure 4 shows the specific arrangement of the strain gauges. Figure 12 depicts the duration curves of the strain of $C 1$ rockfall at different positions with a cushion layer thickness of $0.2 \mathrm{~m}$ and an impact height of $7 \mathrm{~m}$. Among them, S1 S3 and $S 4 \sim S 6$ are the $y$-direction and $x$-direction strains on both sides of the upper surface of the RC slab, respectively. The results reveal that the surface of the RC slab is stretched under compression, the $x$-direction strain is significantly higher than the $y$-direction strain, and the $x$-direction strain peak is in the range of $500-800 \mu \varepsilon$, ultimately obtaining a residual strain in the range of $100-200 \mu \varepsilon$, whereas the strain in the $y$-direction is low. Similarly, S13 S15 and S16 S18 signify the $y$-direction and $x$-direction strains on both sides of the lower surface of the RC slab, respectively. The $x$-direction tensile strains are $27.8 \mu \varepsilon, 68 \mu \varepsilon$, and $22 \mu \varepsilon$, and the $y$ direction strain is significantly lower than the $x$-direction strain. S7 S9 and $S 10 \sim S 12$ are the $x$-direction and $y$-direction strains on the central axis of the lower surface of the RC slab, respectively. Compared with both the sides, the $x$ direction strain value on the central axis increases rapidly, and the maximum strain value is $184 \mu \varepsilon$, which is $170 \%$ higher than its corresponding value on both the sides; however, the $y$-direction strain value is still low. Because the axial strain gauge on the upper surface of the RC slab is mostly damaged under the impact, this will not be discussed in this section. G1 G6 are the strain curves of the lower rebars, and G8 G12 are the strain curves of the upper-layer rebars. Apparently, the strain values of the lower-layer rebars are much higher than the corresponding values of the upperlayer rebars, and the $x$-direction strain values are greater than the $y$-direction strain values. For the upper-layer rebars, the maximum strains of $G 2, G 5$, and G6 are $958 \mu \varepsilon, 770 \mu \varepsilon$, and $898 \mu \varepsilon$, respectively. On the contrary, the corresponding upper-layer rebars $G 8, G 11$, and $G 12$ have maximum strain values of only $34.1 \mu \varepsilon, 49.6 \mu \varepsilon$, and $32.3 \mu \varepsilon$, respectively. Nowadays, in actual engineering applications, the lower layer of a rebar mesh generally has the same specification; however, according to the test results in this study, we recommend further strengthening of the lower layer of the rebar mesh.

3.2.2. Analysis of the Deformation Characteristics of the Concrete Slab. The typical data of the same rockfall at different impact heights are plotted in one coordinate system, as shown in Figure 14. The results show that the deformation characteristics of the RC slab can be divided into three stages: (1) the midpoint deflection rapidly increases from 0 to the peak value; (2) taking the peak value as the boundary, the RC slab starts to rebound, and the midpoint deflection rapidly decreases to 0 and continues to fluctuate for approximately $20 \mathrm{~ms}$ to $50 \mathrm{~ms}$; (3) the fluctuation eventually stabilizes, in which some have residual deformation and others do not.

The experimental results in Figure 14 show that the rockfall weight has a controlling effect on the deformation of 


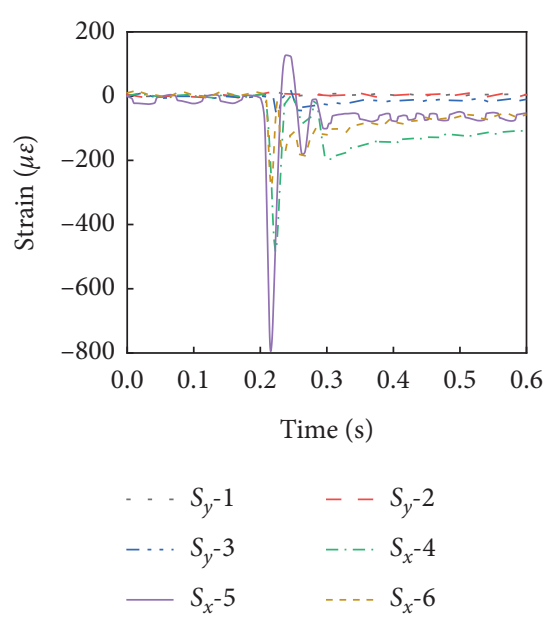

(a)

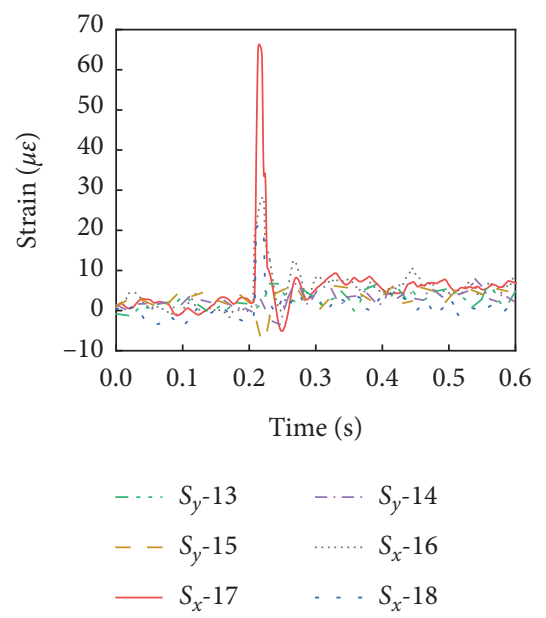

(b)
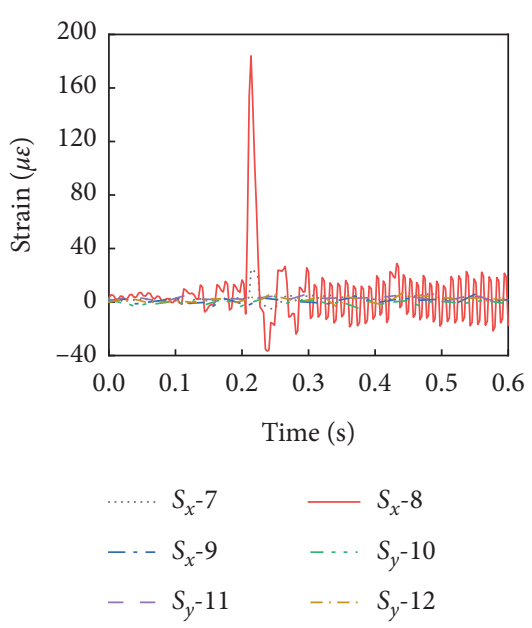

(c)

FIgURE 12: Duration curves of the strain in the concrete slab at different positions (C1-0.2 m-7 m).

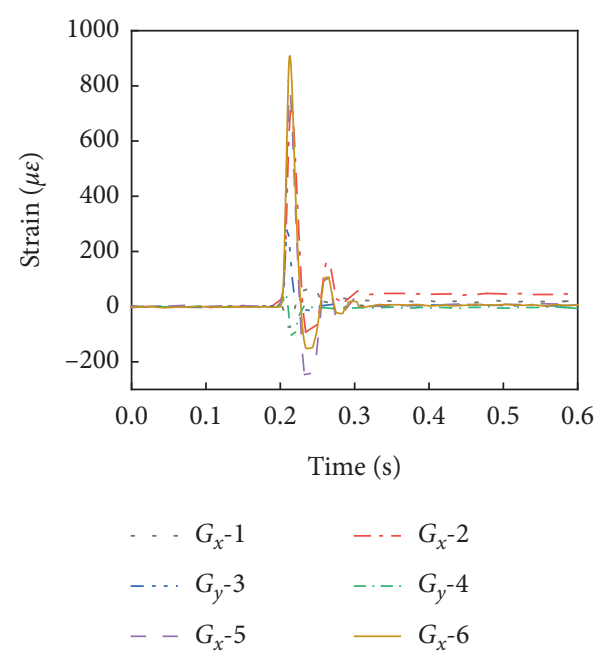

(a)

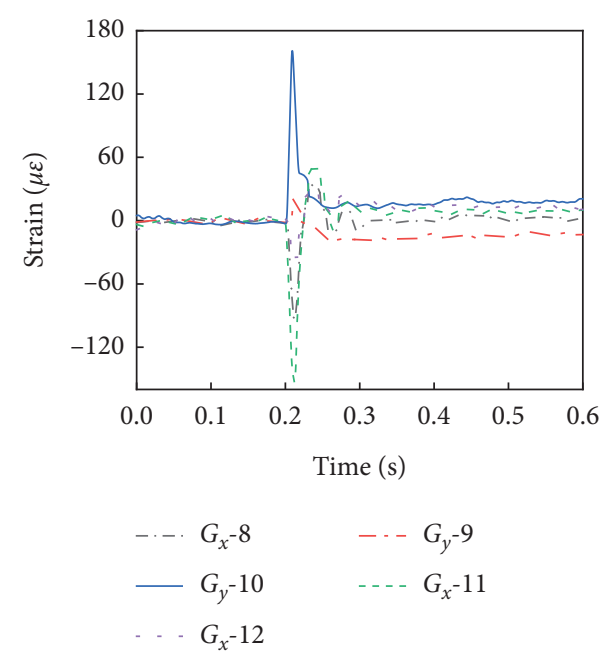

(b)

FIGURE 13: Duration curves of the strain in the rebars at different positions for $C 1-0.2 \mathrm{~m}-7 \mathrm{~m}$.

the RC slab. When the cushion layer thickness is $0.5 \mathrm{~m}$, the peak and residual deformations generated by $C 2$ are much larger than those generated by $C 1$. Under the same rockfall weight, the cushion layer can effectively reduce the midpoint residual deformation, which means its energy dissipation effect is evident. When the cushion layer thickness ranges from $0.5 \mathrm{~m}$ to $0.4 \mathrm{~m}$ and the impact height ranges from $4 \mathrm{~m}$ to $6 \mathrm{~m}$, the residual deformations of the slab are $0.862 \mathrm{~mm}$, $3.23 \mathrm{~mm}, 5.36 \mathrm{~mm}, 2.367 \mathrm{~mm}, 6.74 \mathrm{~mm}$, and $10.53 \mathrm{~mm}$. Evidently, when the cushion layer thickness is reduced by $10 \mathrm{~cm}$, the residual deformation is increased by $174 \%, 108 \%$, and $96 \%$. When the cushion layer thickness is $0.1 \mathrm{~m}$, the deformation curves of $C 1$ and $B 2$ abruptly vary in stage II, which means that the concrete on the lower surface debonds (Figure 15(f)).
In addition, considering larger residual plastic deformations, $C 2$ and $C 1$ rockfalls are selected to plot the plastic deformation histograms at different cushion layer thicknesses (Figures 16(a) and 16(b)), wherein the impact experiment of $C 2$ terminates when the cushion layer thickness is $0.4 \mathrm{~m}$ and the impact height is increased to $6 \mathrm{~m}$. The cumulative residual deformation of the RC slab is approximately $130 \mathrm{~mm}$ at the end (Figure 15(d)). For cushion layer thicknesses of $0.5 \mathrm{~m}$ and $0.4 \mathrm{~m}$, the total plastic deformation produced by $\mathrm{C} 2$ is approximately $50 \mathrm{~mm}$, accounting for $38.5 \%$ in total. As shown in the results (Figure 17), the residual deformations of $C 2$ (cushion layer thicknesses are $0.5 \mathrm{~m}$ and $0.4 \mathrm{~m}$ ) and $C 1$ (cushion layer thickness is $0.1 \mathrm{~m}$ ) conform to an exponential relationship with the impact height. 


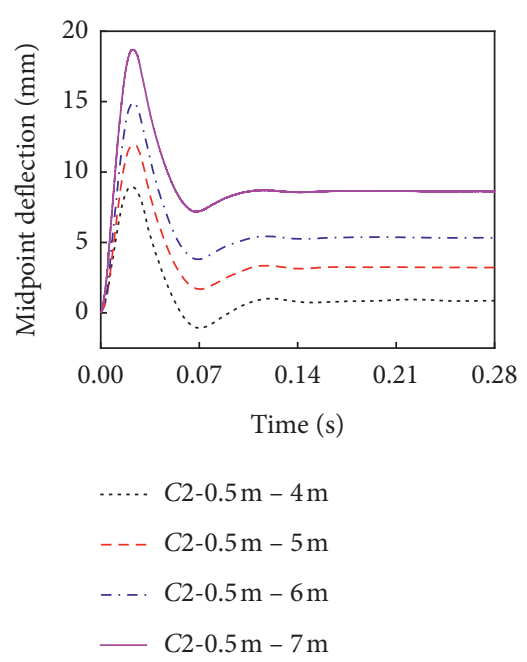

(a)

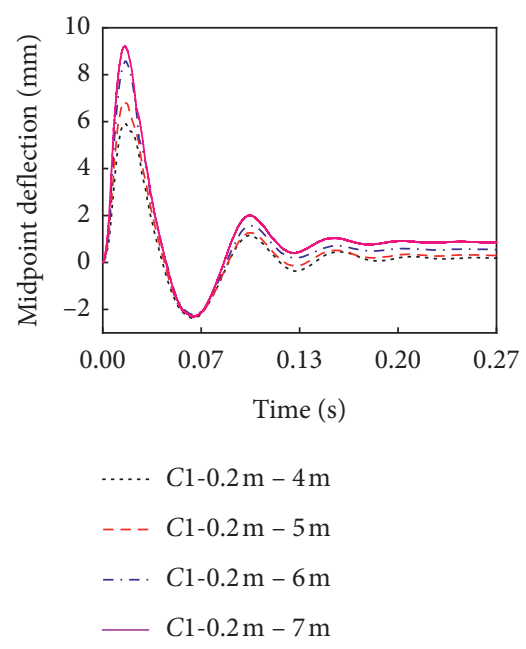

(d)
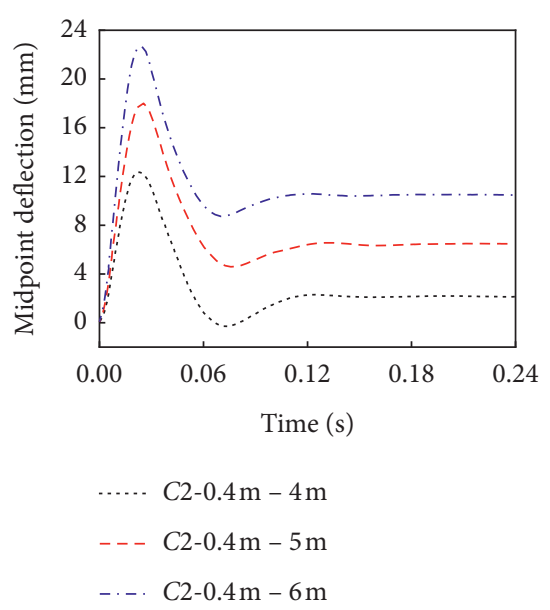

(b)

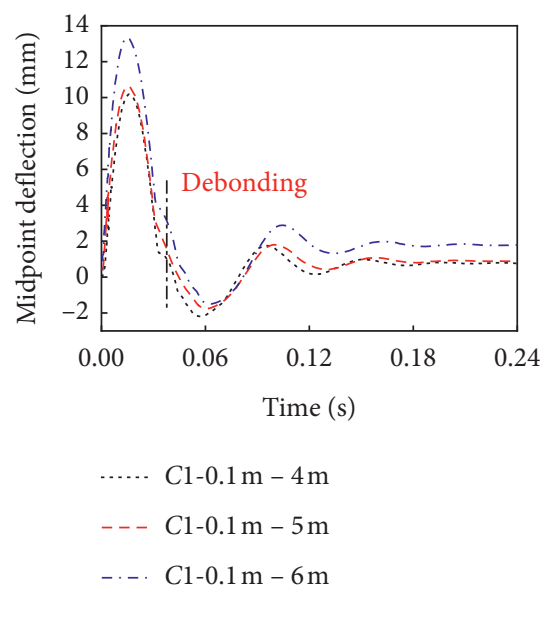

(e)

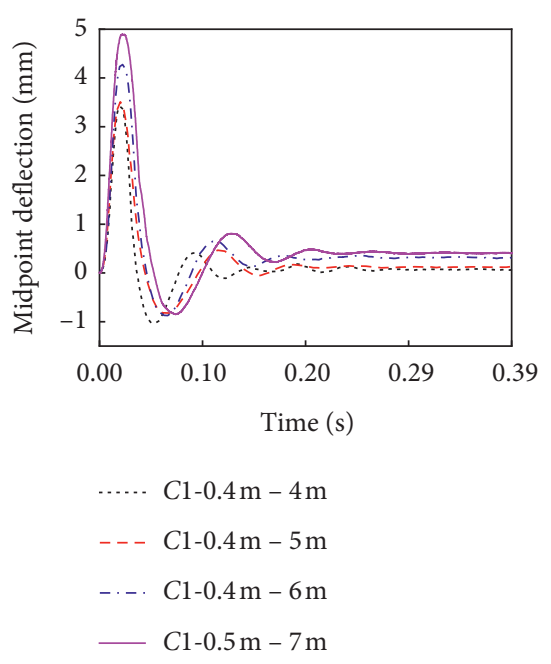

(c)

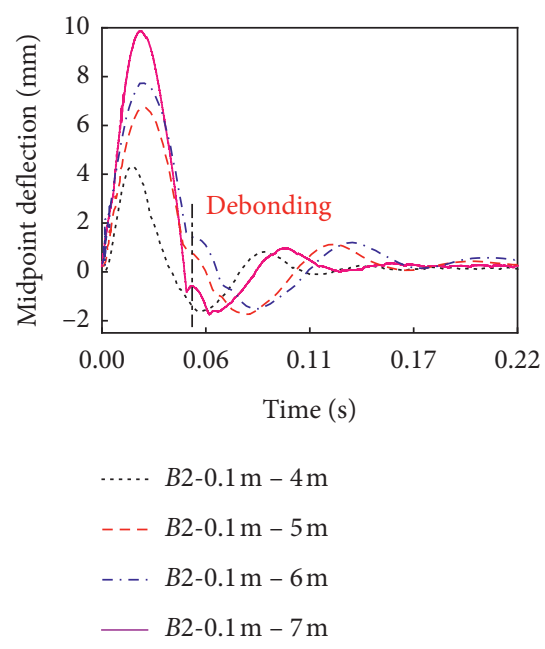

(f)

FIGURE 14: Midpoint deformation characteristics of the RC slab. (a) C2-0.5 m. (b) C2-0.4 m. (c) C1-0.5 m. (d) C1-0.2 m. (e) C1-0.1 m. (f) $B 2-0.1 \mathrm{~m}$.

Table 3 summarizes the four typical sets of experimental data in the order of the impact time. Comparing the data of C1-0.5 $\mathrm{m}$ and $B 2-0.3 \mathrm{~m}$, it is found that although $C 1$ with a larger weight has a much higher incident impact force than $B 2$, the variation in the cushion layer thickness levels down the difference in their transmitted forces, which is specifically manifested in the fact that the strain values of each measuring point and the maximum midpoint deformation of the RC slab are the same. Here, the concrete strain measurement point $S 8$ is taken as an example. When the impact height is between $5 \mathrm{~m}$ and $7 \mathrm{~m}$, the corresponding strain values under $C 1-0.5 \mathrm{~m}$ impact conditions are $102.3 \mu \varepsilon$, $126.9 \mu \varepsilon$, and $164.0 \mu \varepsilon$, respectively, and under $B 2-0.3 \mathrm{~m}$ impact conditions, the strain values are $112.2 \mu \varepsilon, 126.1 \mu \varepsilon$, and $147.6 \mu \varepsilon$, respectively. Therefore, the attenuation theory in this paper can reasonably reflect the energy distribution under different impact conditions.

C2-0.5 $\mathrm{m}$ strain and deformation data are collected at the end of concrete failure. As the measuring points reveal, the strain values of the rebar and concrete generally increase. Among them, the measuring points of $S 8$ and $S 11$ in the midspan increase very rapidly. In addition to the high energy absorbed by the RC slab, the accumulated energy in the early stage may cause the concrete to yield. The specific result is that significant amounts of irreversible strains and residual deformations are generated, as shown in Figure 18. The strain rebound at the measuring point is small, and the peak strain is approximately equal to the residual strain.

3.2.3. Crack Development and Failure Analysis. Through the calculation based on the rockfall weight and impact height, the entire experiment produces approximately $600 \mathrm{~kJ}$ of energy. During the impact process, a part of the energy is dissipated by the cushion layer, and the rest is absorbed by the RC slab. Figure 15 depicts the formation and expansion processes of the cracks in the RC slab with the increase in the cumulative impact energy level. Stage I (development of a 

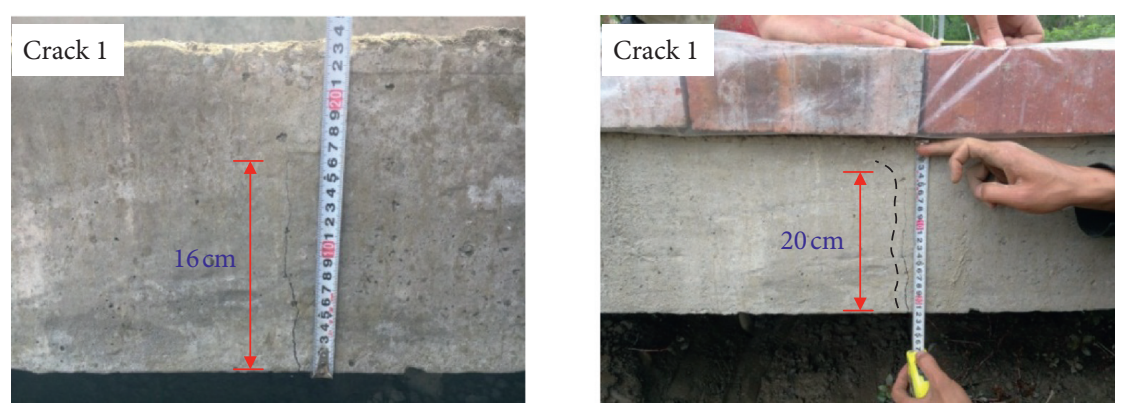

(a)

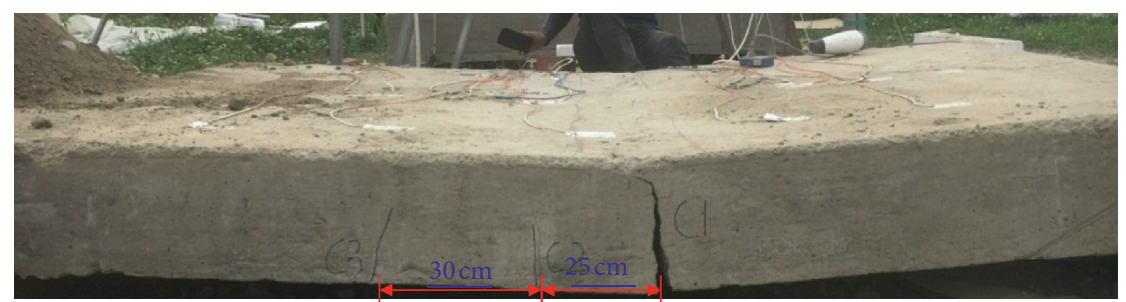

(b)

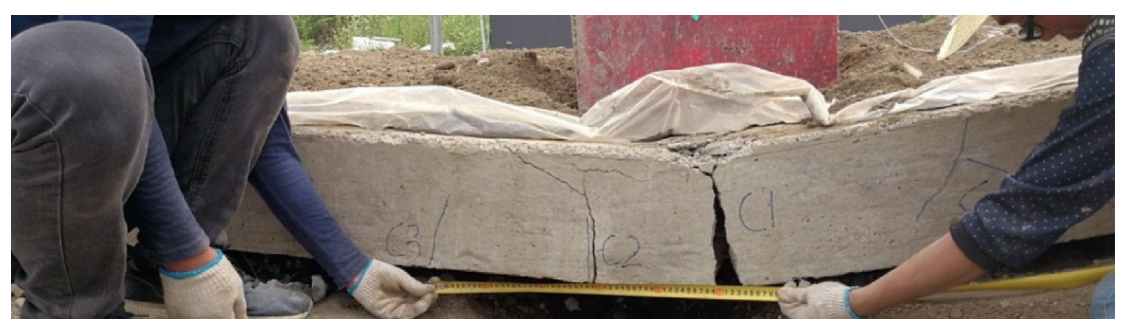

(c)

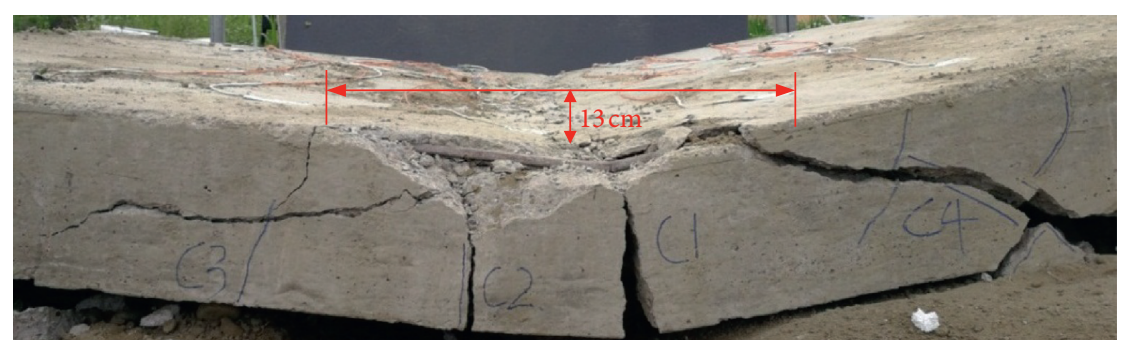

(d)

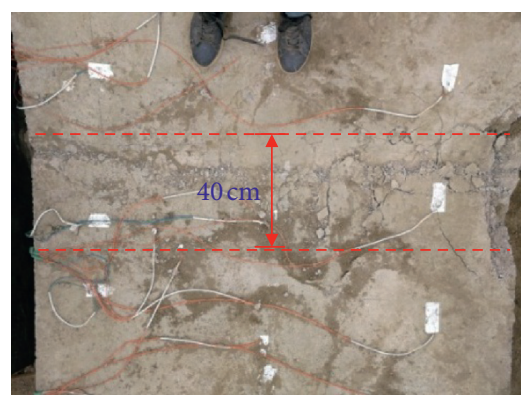

(e)

FIgURe 15: Continued. 


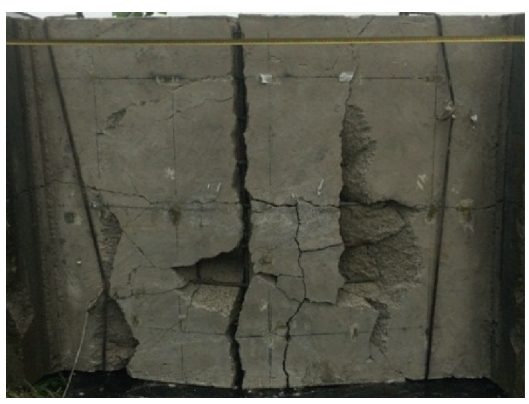

(f)

FIgURE 15: The RC slab failure process. (a) Development of the main bending crack. (b) Generation and expansion of secondary bending cracks. (c) Shear crack generation and midspan bending crack penetration. (d) Complete failure. (e) Ultimate morphology of the upper surface of the RC slab. (f) Ultimate morphology of the lower surface of the RC slab.

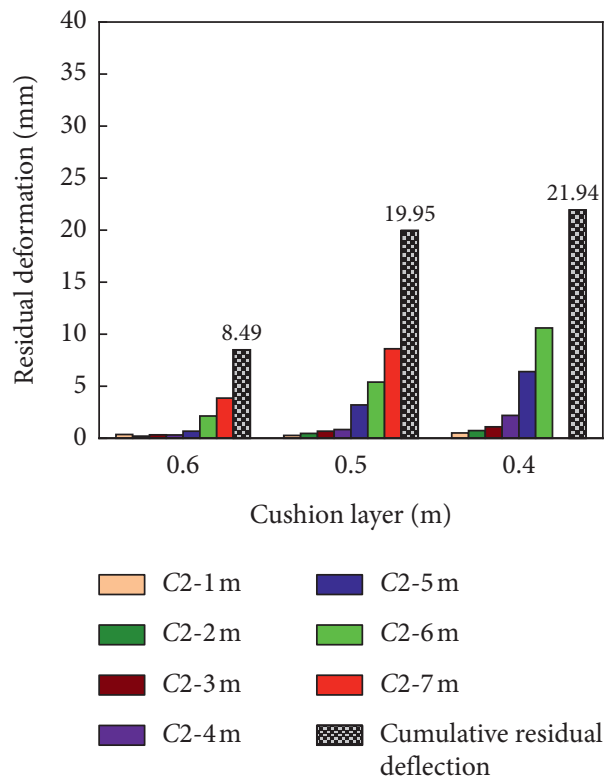

(a)

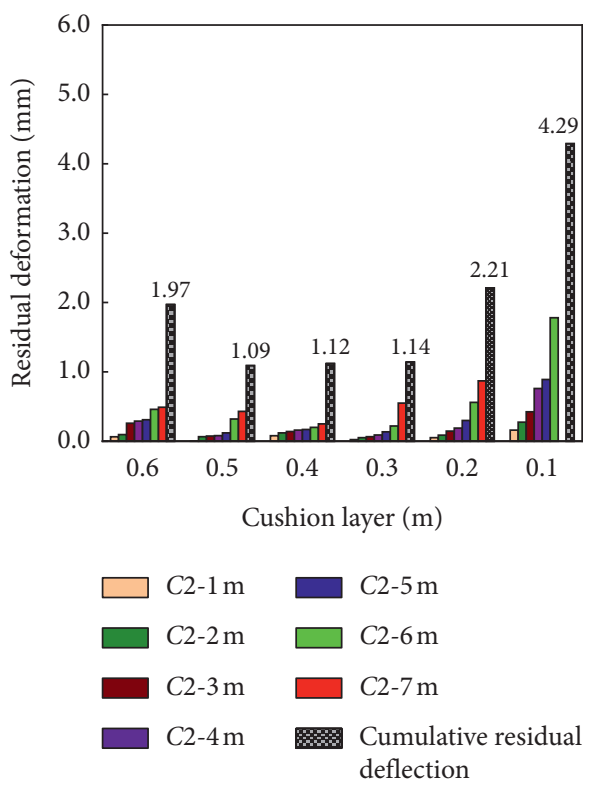

(b)

FIgURE 16: Plastic deformation under different cushion layer thicknesses and impact heights. (a) Midpoint plastic deformation of C2. (b) Midpoint plastic deformation of $C 1$.

main bending crack (Figure 15(a)): the initial deformation begins with the occurrence of a midspan bending crack (Crack 1) at the bottom of the RC slab. As the cumulative impact energy increases, the crack extends vertically up to $20 \mathrm{~cm}$, with a width of less than $1 \mathrm{~mm}$, and the midspan plastic deformation is small. In this stage, the RC slab is in the bending deformation mode. According to the calculation using $\eta$, the cumulative impact energy is in the range of $160-200 \mathrm{~kJ}$, and the energy absorbed by the RC slab is in the range of 70-160 kJ. Stage II (generation and expansion of secondary bending cracks): as the cushion layer thickness further decreases and the cumulative energy increases accordingly, the midspan main bending crack almost penetrates the upper surface of the RC slab. Thereafter, secondary bending cracks start to occur along its two sides, such as Crack 2 and Crack 3, as shown in Figure 15(b). In contrast to
Stage I, the width of the midspan main bending crack increases sharply from $0.8 \mathrm{~mm}$ to $12 \mathrm{~mm}$ in this stage. The energy absorbed by the RC slab largely contributes to the widening of the midspan main bending crack and generation of secondary bending cracks, and the failure of the RC slab still belongs to the bending deformation mode. In addition, the cumulative impact energy in this stage is in the range of $100-150 \mathrm{~kJ}$, and the RC slab absorbs the energy in the range of $40-80 \mathrm{~kJ}$. Stage III (shear crack generation and midspan bending crack penetration (Figure 15(c)): as the cushion layer thickness is reduced, the cumulative energy is further increased and Crack 1 is further enlarged accordingly, while evident oblique shear cracks and some randomly distributed bilateral pinnate cracks are generated in the midspan of the $\mathrm{RC}$ slab. In this stage, the RC slab shows both bending and shear deformation characteristics, and the concrete on the 


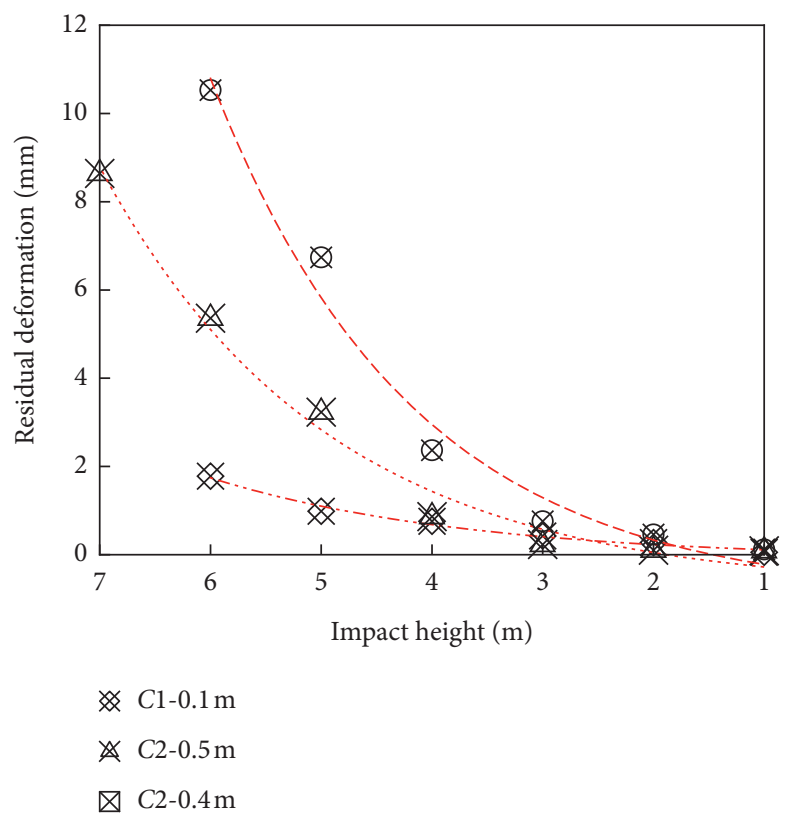

FIGURE 17: The relationship between the residual deformation and impact height.

TABLE 3: Typical experimental data.

\begin{tabular}{|c|c|c|c|c|c|c|c|c|c|c|c|c|c|}
\hline \multirow[t]{2}{*}{ Group number } & \multirow[t]{2}{*}{ Impact height $(\mathrm{m})$} & \multicolumn{2}{|c|}{$\begin{array}{c}\text { Impact } \\
\text { force }(\mathrm{kN})\end{array}$} & \multirow{2}{*}{$\eta$} & \multicolumn{4}{|c|}{ Concrete strain $(\mu \varepsilon)$} & \multicolumn{4}{|c|}{ Rebar strain $(\mu \varepsilon)$} & \multirow{2}{*}{ Deformation $(\mathrm{mm})$} \\
\hline & & $F_{0}$ & $F_{1}$ & & $S_{x}-8$ & $S_{y}-11$ & $S_{y}-14$ & $S_{x}-17$ & $G_{x}-2$ & $G_{x}-6$ & $G_{y}-10$ & $G_{x}-11$ & \\
\hline \multirow{3}{*}{$C 1-0.5 \mathrm{~m}$} & 5 & 107.6 & 28.5 & 26.5 & 102.3 & 20.5 & 24.8 & 56.2 & 324.8 & 489.7 & 47.2 & 20.0 & 3.42 \\
\hline & 6 & 127.1 & 39.8 & 31.3 & 126.9 & 23.5 & 25.3 & 67.4 & 409.4 & 603.0 & 65.0 & 45.3 & 4.28 \\
\hline & 7 & 146.0 & 52.7 & 36.1 & 164.0 & 27.2 & 26.4 & 76.0 & 482.7 & 667.5 & 75.9 & 76.0 & 4.89 \\
\hline \multirow{3}{*}{$B 1-0.3 \mathrm{~m}$} & 5 & 36.2 & 14.2 & 39.2 & 61.4 & 5.3 & 3.0 & 4.4 & 191.0 & 171.7 & 23.3 & 10.2 & 1.41 \\
\hline & 6 & 40.1 & 17.9 & 44.6 & 70.0 & 6.7 & 6.8 & 7.5 & 209.6 & 183.0 & 37.2 & 17.5 & 1.57 \\
\hline & 7 & 42.4 & 20.8 & 49.1 & 77.2 & 8.4 & 8.3 & 11.6 & 225.9 & 210.2 & 42.6 & 21.0 & 1.72 \\
\hline \multirow{3}{*}{$B 2-0.3 \mathrm{~m}$} & 5 & 58.5 & 22.5 & 38.5 & 112.2 & 5.7 & 4.5 & 25.0 & 362.1 & 397.2 & 54.1 & 21.2 & 2.83 \\
\hline & 6 & 67.1 & 28.2 & 42.0 & 126.1 & 4.0 & 7.1 & 31.3 & 385.2 & 449.9 & 124.2 & 28.8 & 3.20 \\
\hline & 7 & 76.6 & 35.0 & 45.7 & 147.6 & 10.7 & 9.1 & 34.2 & 414.5 & 488.1 & 147.1 & 43.9 & 3.45 \\
\hline \multirow{3}{*}{$C 2-0.5 \mathrm{~m}$} & 5 & 224.2 & 60.7 & 27.1 & 555.0 & 152.5 & 9.3 & 72.2 & 472.8 & 1321.2 & 545.0 & 164.8 & 11.96 \\
\hline & 6 & 239.9 & 80.1 & 33.4 & 910.8 & 221.8 & 13.8 & 133.1 & 1103.4 & 1369.1 & 728.0 & 204.7 & 14.94 \\
\hline & 7 & 263.9 & 99.5 & 37.7 & 947.0 & 256.0 & 17.7 & 511.3 & 1250.5 & 1526.3 & 1041.2 & 244.2 & 18.69 \\
\hline
\end{tabular}

lower surface of the RC slab debonds. The corresponding cumulative impact energy is in the range of $50-100 \mathrm{~kJ}$, and the RC slab absorbs energy in the range of 30-70 kJ. Stage IV (complete failure): in the later stages of the impact experiment, under the impact condition of $C 2-0.4 \mathrm{~m}$, the width of Crack 1 does not increase significantly, but evident oblique shear cracks occur (Figure 15(d)). The surrounding pinnate cracks become denser and wider, and the bending cracks are connected to the shear cracks. Overall, the RC slab "snaps" along the $y$-direction in the midspan, exhibiting typical bending failure characteristics. This process corresponds to a cumulative impact energy of approximately $50 \mathrm{~kJ}$, and the concrete slab absorbs approximately $30 \mathrm{~kJ}$ of energy.
Figures 15(e) and 15(f) show the ultimate failure modes of the lower surface of the RC slab. The RC slab surface is crushed because of the compressive stress, and the crushing range is highly concentrated and symmetrically distributed in the range of $40 \mathrm{~cm}$ across the midspan axis. Additionally, a large amount of peeling concrete debris can be observed. Outside the range, the surface morphology of the RC slab is intact; however, there is evident residual deformation, and the further away from the midspan axis, the smaller the residual deformation. The lower surface of the $\mathrm{RC}$ slab forms a longitudinal wide tensile crack. As a result of the large area of concrete collapse, a collapse pit is formed. Moreover, a number of transverse cracks perpendicular to the 


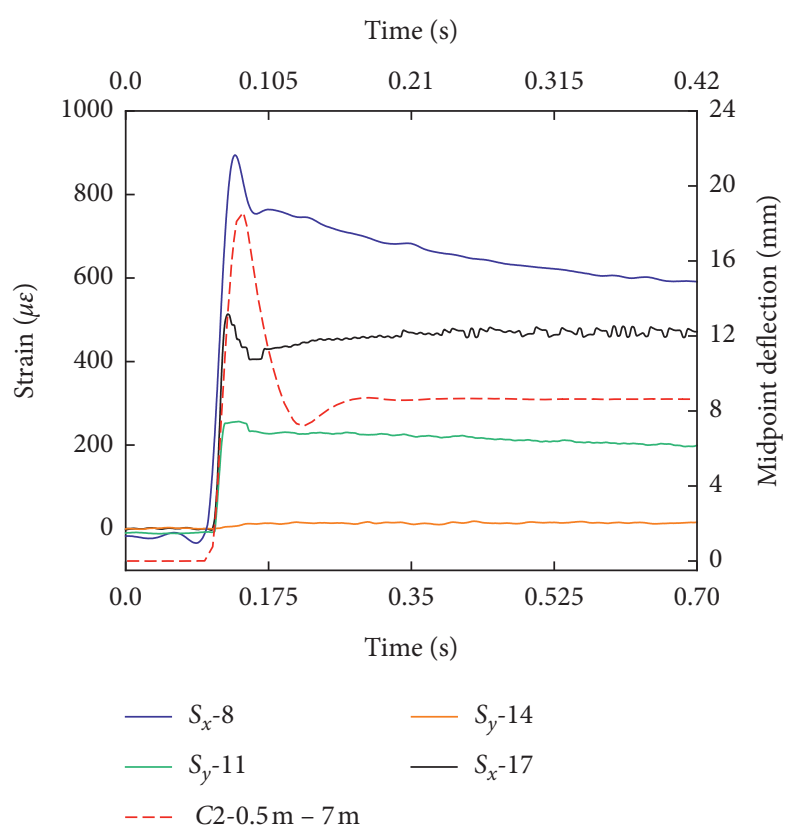

Figure 18: Strain and midpoint deformation of the RC slab for C2-0.5 m-7 m.

longitudinal cracks are distributed on the lower surface of the RC slab; however, the width and extent of the crack are far less than those of the midspan longitudinal cracks.

\section{Discussion}

In this study, the dynamic responses of spherical and cubic rockfalls to the structure were investigated. It is worth noting that some studies have shown that the shape of rockfalls will affect the impact characteristic quantities. Roethlin et al. [43] observed that the shape of rockfalls would affect the stress distribution characteristics in the contact area and the arrangement of particles. In addition, for the rockfalls of the same weight and impact speed, cubic rocks have shorter contact time and greater peak impact force than spherical rocks [44]. More information about the influence of rockfall shape on impact dynamic response is analyzed by numerical simulation $[45,46]$ because numerical simulation can control variables better and get more details. We designed two different types of rockfalls in the initial design of the experiment, in order to find more convincing evidence through experiments than numerical simulations. Unfortunately, due to the relatively large size of the model and experimental errors, the experimental results only obtained the law of the influence of the rockfall shape on the crater (Figure 7), and the influence on other characteristic quantities (such as contact time and contact force) is not significant.

Generally, actual rockfalls undergo oblique collisions at any angle. In our experiment, only free-fall frontal collisions were considered. Under the same impact velocity, a frontal collision produces the highest impact force, which is a safer consideration for the structural design. In addition, for the diffusion angle of the impact force in the cushion layer, we used an empirical calculation method related to the internal friction angle of the soil, which has been proven to be scientific in many studies $[39,47]$. Finally, we only discussed $\mathrm{RC}$ slabs with a thickness of $0.25 \mathrm{~m}$. The actual results of similar tests on RC slabs with a thickness of $0.35 \mathrm{~m}$ show that the failure modes and rupture depth of the concrete slabs are different. Under approximately the same level of energy impact, the $0.35 \mathrm{~m}$ thick RC slab will only undergo bending failure without any shear cracks. The subsequent reports will focus on the relevant differences.

\section{Conclusion}

From the results of tests conducted on rockfalls impacting a concrete slab covered with a sand cushion layer, the following conclusions can be drawn. (1) The cushion layer thickness exerts a significant influence on the impact force. Within a certain range, increasing the cushion layer thickness can effectively reduce the impact force. Generally, the impact force of rockfalls acting on a cushion layer surface exhibits an exponential relationship with the cushion layer thickness. In this study, when the cushion layer thickness was reduced from $0.3 \mathrm{~m}$ to $0.2 \mathrm{~m}$, the impact force increased significantly, whereas the impact duration decreased significantly, indicating that the optimal cushion layer thickness can be set to $0.3 \mathrm{~m}$. (2) An empirical formula was used to predict the maximum penetration of the rockfall impacting the cushion layer, and the measured data were consistent with the results calculated using the empirical formula. (3) There exists an exponential relationship between the transmission of the impact force in the cushion layer and cushion layer thickness. When the cushion layer thickness was $0.3 \mathrm{~m}$, the incident impact force was reduced by approximately $30 \%$. When the cushion layer thickness was further increased to $0.6 \mathrm{~m}$, the incident impact force was approximately reduced by $70 \%$. This proves that the energy 
dissipation effect of the cushion layer is significant. (4) Based on the strain response characteristics of the measuring points, the strain values of the rebars in the lower layer were significantly higher than those in the upper layer. The authors recommend increasing the diameter and strength of the lower layer of the rebar mesh in practical engineering applications. (5) With the increase in the cumulative impact energy, the RC slab undergoes the development of a main bending crack, generation and expansion of secondary bending cracks, shear crack generation and midspan bending crack penetration, and complete failure. At the end of the impact experiment, the RC slab exhibited both bending and shear cracks. At a macrolevel, the RC slab "snapped" along the $y$-direction in the midspan, exhibiting typical bending failure characteristics.

\section{Data Availability}

The data used to support the findings of this study are available from the corresponding author upon request.

\section{Conflicts of Interest}

The authors declare that there are no conflicts of interest regarding the publication of this paper.

\section{Acknowledgments}

This work was supported by the National Natural Science Foundation of China (41672283 and 41731285) and Major Scientific and Technological Support Research Subject for the Prevention and Control of Ecological Geological Disasters in "8.8" Jiuzhaigou Earthquake Stricken Area of Department of Natural Resources of Sichuan Province (KJ2018-20).

\section{References}

[1] J. Glover, P. Bartelt, M. Christen, and W. Gerber, "Rockfallsimulation with irregular rock blocks," Engineering Geology for Society and Territory, vol. 2, pp. 1729-1733, 2015.

[2] P. Zhao, L. Xie, L. Li, Q. Liu, and S. Yuan, "Large-scale rockfall impact experiments on a RC rock-shed with a newly proposed cushion layer composed of sand and EPE," Engineering Structures, vol. 175, pp. 386-398, 2018.

[3] G. S. Wang, Y. H. Sun, A. Zhang et al., "Study on the impact resistance of metal flexible net to rock fall," Shock and Vibration, vol. 2020, Article ID 9612405, 11 pages, 2021.

[4] L. M. Cui, M. Wang, and T. R. Yu, "Dynamic finite element analysis of a new type flexible rock shed under the impact of rock block and improving the design," Shock and Vibration, vol. 2018, Article ID 1936560, 16 pages, 2018.

[5] J. H. Sun, Z. J. Chu, Y. F. Liu et al., "Performance of used tire cushion layer under rockfall impact," Shock and Vibration, vol. 2016, Article ID 8760592, 10 pages, 2016.

[6] N. Kishi, H. Konno, K. Ikeda et al., "Prototype impact tests on ultimate impact resistance of PC rock-sheds," International Journal of Impact Engineering, vol. 27, no. 9, pp. 969-985, 2016.

[7] C. Ronco, C. Oggeri, and D. Peila, "Design of reinforced ground embankments used for rockfall protection," Natural
Hazards and Earth System Sciences, vol. 9, no. 4, pp. 11891199, 2009.

[8] M. Spadari, A. Giacomini, O. Buzzi et al., "Prediction of the bullet effect for rockfall barriers:a scaling approach," Rock Mechanics and Rock Engineering, vol. 45, no. 2, pp. 131-144, 2012.

[9] S. Lambert and F. Bourrier, "Design of rockfall protection embankments: a review," Engineering Geology, vol. 154, pp. 77-88, 2013.

[10] C. D. Prisco and M. Vecchiotti, "Design charts for evaluating impact forces on dissipative granular soil cushions," Journal of Geotechnical and Geoenvironmental Engineering, vol. 136, no. 11, pp. 1529-1541, 2010.

[11] X. W. Hu, X. F. Mei, Y. Yang et al., "Dynamic response of pileplate rock retaining wall under impact of rockfall," Journal of Engineering Geology, vol. 27, no. 1, pp. 123-133, 2019.

[12] S. M. He and Y. Wu, "Research on cushioning mechanism of new-typed energy dissipative rock shed," Chinese Journal of Rock Mechanics and Engineering, vol. 29, no. 5, pp. 926-932, 2010.

[13] Z. Boukria, P. Perrotin, A. Bennani, and A. Limam, "Experimental impact characterization on a structurally dissipating rock-shed (SDR) structure," International Journal of Protective Structures, vol. 3, no. 1, pp. 21-36, 2012.

[14] J. Su, C. Zhou, S. S. Chen et al., "Numerical simulation of flexible gabion arch dam to prevent and control debris flow blocks," Chinese Journal of Geotechnical Engineering, vol. 37, no. 2, pp. 269-275, 2015.

[15] X. Yu, L. Chen, and Q. Fang, "Experimental study on the attenuation of stress wave in coral sand," Chinese Journal of Rock Mechanics and Engineering, vol. 37, no. 6, pp. 1520-1529, 2018.

[16] H. Luo, W. L. Cooper, and H. Lu, "Effects of particle size and moisture on the compressive behavior of dense Eglin sand under confinement at high strain rates," International Journal of Impact Engineering, vol. 65, no. 65, pp. 40-55, 2014.

[17] J. C. Li and G. W. Ma, "Experimental study of stress wave propagation across a filled rock joint," International Journal of Rock Mechanics and Mining Sciences, vol. 46, no. 3, pp. 471478, 2009.

[18] T. S. Ho, H. Masuya, and N. Takashita, "Experimental study concerning impact characteristics by collision of weight on sand cushion over steel beam," International Journal of Geomate, vol. 4, no. 1, pp. 471-476, 2013.

[19] D. P. Visco, S. Saravanan, T. R. K. Mohan et al., "Impulse penetration into idealized granular beds: behavior of cumulative surface kinetic energy," Physical Review E, vol. 70, no. 1, pp. 1-7, 2004.

[20] W. Gerber, A. Volkwein, and M. Denk, "Impact of rockfalls on reinforced foam glass cushion systems," in Proceedings of the InterdisciplinaryWorkshop on Rockfall Protection, A. Volkwein, V. Labiouse, and K. Schellenberg, Eds., pp. 31-33, Morschach, Switzerland, June 2008.

[21] H. Y. Gao, Z. X. Liu, Y. K. Yang et al., "Blast-resistant performance of aluminum foam-protected reinforced concrete slabs," Explosion and Shock Waves, vol. 39, no. 2, pp. 30-41, 2019.

[22] D. P. Wang, S. M. He, Y. Wu et al., "Cusioning effect of rock sheds with EPS cushion on rock-falls action," Journal of Vibration and Shock, vol. 33, no. 4, pp. 199-214, 2014.

[23] F. Calvetti, C. D. Prisco, and M. Vecchiotti, "Experimental and numerical study of rock-fall impacts on granular soils," Rivista Italiana Di Geotecnica, vol. 39, no. 4, pp. 95-109, 2005. 
[24] J. Lorentz, P. Perrotin, and F. Donz'e, "A new sandwich design structure for protection against rockfalls," in Proceedings of the InterdisciplinaryWorkshop on Rockfall Protection, A. Volkwein, V. Labiouse, and K. Schellenberg, Eds., pp. 58-60, Morschach, Switzerland, June 2008.

[25] N. Kishi, O. Nakano, H. Mikami et al., "Field test on shock absorbing effect of three-layered absorbing system," in Proceedings of the Transactions of the 12 International Conference on Structural Mechanics in Reactor Technology (SMiRT), IASMiRT, Stuttgart, Germany, 1993.

[26] "Ministry of transport of the people's Republic of China," Guidelines for Design of Highway Tunnel (JTG/T D70-2010), People Communications Press Co. Ltd., Beijing, China, 2010.

[27] B. Belhadj, M. Bederina, K. Benguettache et al., "Effect of the type of sand on the fracture and mechanical properties of sand concrete," Advances in Concrete Construction, vol. 2, no. 1, pp. 13-27, 2014.

[28] S. S. Karanth, V. G. Ghorpade, and H. S. Rao, "Shear and impact strength of waste plastic fibre reinforced concrete," Advances in Concrete Construction, vol. 5, no. 2, pp. 173-182, 2017.

[29] E. Dimnet, E. Haza-Rozier, G. Vinceslas et al., "Experimental and numerical study of a shock-absorbing structure," Acta Mechanica, vol. 224, no. 12, pp. 3037-3055, 2013.

[30] F. Bourrier, S. Lambert, A. Heymann et al., "How multi-scale approaches can benefit the design of cellular rockfall protection structures," Canadian Geotechnical Journal, vol. 48, no. 12, pp. 1803-1816, 2011.

[31] B. Wang and D. S. Cavers, "A simplified approach for rockfall ground penetration and impact stress calculations," Landslides, vol. 5, no. 3, pp. 305-310, 2008.

[32] S. Zhang, J. F. Zhang, L. Tao et al., "Tests for cushion performance of a protective layer with S-shaped steel joist and sandwich slab under rockfall impact," Journal of Vibration and Shock, vol. 36, no. 24, pp. 148-155, 2017.

[33] S. Kawahara and T. Muro, "Effects of dry density and thickness of sandy soil on impact response due to rockfall," Journal of Terramechanics, vol. 43, no. 3, pp. 329-340, 2006.

[34] H. Othman and H. Marzouk, "An experimental investigation on the effect of steel reinforcement on impact response of reinforced concrete plates," International Journal of Impact Engineering, vol. 88, pp. 12-21, 2016.

[35] V. Labiouse, F. Descoeudres, and S. Montani, "Experimental study of rock sheds impacted by rock blocks," Structural Engineering International, vol. 63, no. 3, pp. 171-176, 2008.

[36] X. Wang, T. Y. Zhou, J. T. Shi et al., "Theoretical and LSDYNA simulation study of based on the theory of free-fall rockfall's impacton soil layer," Journal of Beijing Jiao Tong University, vol. 43, no. 4, pp. 9-19, 2019.

[37] Ministry of Transport of the People's Republic of China, Specifications For Design Of Highway Subgrades (JTG D302015), People Communications Press Co. Ltd., Beijing, China, 2015.

[38] The Second Railways Survery and Design Institute, TB100032005 Railways Tunnel Design Code, China Railway Publishing House, Beijing, China, 2005.

[39] S. Q. Ye, H. K. Chen, and H. M. Tang, "The Calculation Method for the impact force of rockfall," Chinese Railway Science, vol. 31, no. 6, pp. 56-62, 2010.

[40] S. M. He, J. Shen, and Y. Wu, "Rock shed dynamic response toimpact of rock-fall," Rock and Soil Mechanics, vol. 32, no. 3, pp. 781-788, 2011.
[41] Q. X. Yang and B. S. Guan, "Test andresearch on calculating method of falling stone impulsive force," Railway Society, vol. 18, no. 1, pp. 101-106, 1996.

[42] X. J. Pei, Y. Liu, and D. P Wang, "Study onthe energy dissipation of sandy soil cushions on therock-shed under rockfall impact load," Journal Of Sichuan University (Engineering Science Edition), vol. 48, no. 1, pp. 15-22, 2016.

[43] C. Roethlin, F. Calvetti, S. Yamaguchi et al., "Numerical simulation of rockfall impact on a rigid reinforced concrete slab with a cushion layer," in Proceedings of the Fourth International Workshop on Performance, Protection and Strengthening of Structures, Mysore, India, August 2013.

[44] P. Yan, J. Zhang, Q. Fang, and Y. Zhang, "Numerical simulation of the effects of falling rock's shape and impact pose on impact force and response of RC slabs," Construction and Building Materials, vol. 160, pp. 497-504, 2018.

[45] C. Chen, C. Q. Liu, L. Y. Chen et al., "Study on impact force of rock-fall onto rock shed tunnel," Journal of Highway and Transportation Research and Development, vol. 32, no. 1, pp. 102-109, 2015.

[46] W. Shen, T. Zhao, F. Dai, M. Jiang, and G. G. D. Zhou, "DEM analyses of rock block shape effect on the response of rockfall impact against a soil buffering layer," Engineering Geology, vol. 249, pp. 60-70, 2019.

[47] N. N. Wang, W. Jiang, Y. H. Wang et al., "Study on the diffusion characteristics of rockfall impacting load in cushion soil," Journal Of China Three Gorges University (Natural Sciences), vol. 42, no. 2, pp. 46-51, 2020. 